\title{
Critical Assessment of the Efficiency of Chitosan Biohydrogel Beads as Recyclable and Heterogeneous Organocatalyst for $\mathrm{C}-\mathrm{C}$ Bond Formation
}

\author{
Dennis Kühbeck, ${ }^{a}$ G. Saidulu, ${ }^{b}$ K. Rajender Reddy ${ }^{b}$ and David Díaz Díaz*a,c \\ s Received (in $X X X, X X X)$ Xth $X X X X X X X X X 20 X X$, Accepted $X$ th $X X X X X X X X X 20 X X$ \\ DOI: $10.1039 / b 000000 x$
}

The effectiveness of neutral $\mathrm{pH}$ chitosan hydrogel beads (CSHB) as a green organocatalyst for a variety of $\mathrm{C}-\mathrm{C}$ bond forming reactions (i.e. aldol reaction, Knoevenagel condensation, nitroaldol (Henry) reaction, Michael addition) has been comprehensively evaluated. Reaction rates, conversions and 10 selectivities were studied in function of a series of input variables including size, $\mathrm{pH}$ and reactive surface area of the beads, catalyst loading, temperature, molecular weight of the biopolymer, concentration, solvent system and molar ratio of reactants. Moreover, the catalytic biohydrogel beads were characterized by a variety of techniques including, among others, SEM, FT-IR, TGA and DSC.

\section{Introduction}

${ }_{15}$ With growing concern for our environment and stringent environmental regulations by the governments, emphasis of science and technology is shifting more and more from petrochemical-based feedstocks towards the optimal use of environmentally friendly and sustainable resources and ${ }_{20}$ processes. $^{1}$ In this regard, direct utilization of products derived from naturally occurring materials has become a prevalent means for a number of high-tech applications.

Within this context, and during the past few decades, biopolymers have attracted increasing attention in both academic 25 and industrial worlds owing to their unique properties, such as biodegradability, biocompatibility and antibacterial activity. ${ }^{2}$ Among these biopolymers, cellulose and chitin are the most important biomass resources and the most abundant organic compounds on Earth. ${ }^{3}$ Chitin, $\operatorname{poly}(\beta-(1 \rightarrow 4)-N$-acetyl-D${ }_{30}$ glucosamine), is the main component of the cell walls of fungi, the exoskeletons of arthropods such as crustaceans and insects, the radulas of molluscs and the beaks of cephalopods. ${ }^{4}$ Depending on its source, chitin occurs as two allomorphs, namely the $\alpha$ and $\beta$ forms, and it is usually extracted by acid treatment to dissolve 35 calcium carbonate followed by alkaline treatment to solubilise proteins. ${ }^{5}$ Chitosan, the most important derivative of chitin, can be obtained by extensive deacetylation under alkaline conditions

\footnotetext{
a Institut für Organische Chemie, Universität Regensburg, Universitätsstr. 31, 93040 Regensburg, Germany.

E-mail: David.Diaz@chemie.uni-regensburg.de; Fax: + 49941 9434121; Tel.: + 499419434373

${ }^{b}$ Inorganic and Physical Chemistry Division, Indian Institute of Chemical Technology, Tarnaka, Hyderabad 500 607, India

${ }^{c}$ ISQCH, Universidad de Zaragoza-CSIC, 50009 Zaragoza, Spain

† Electronic Supplementary Information (ESI) available: Selected NMR spectra, DSC thermograms, UV-vis studies and additional figures. See DOI: $10.1039 / \mathrm{b} 000000 \mathrm{x} /$
}

(Fig. 1). ${ }^{6}$ However, chitosan is rarely $100 \%$ deacetylated resulting actually in a hydrophilic random copolymer of $\beta$-(1-4)-linked ${ }_{40}$ glucosamine (deacetylated unit) and $N$-acetyl-D-glucosamine (acetylated unit). Their relative ratio defines the degree of deacetylation (DDA) that controls important properties of the polymer such as its basicity, viscosity and solubility, which are also influenced by the polymer's molecular weight. ${ }^{7}$ Indeed, the ${ }_{45}$ intrinsic $\mathrm{p} K_{\mathrm{a}}$ of chitosan depends on the DDA, the ionic strength and the charge neutralization of amine groups. In practice, it usually lies within 6.3-6.7 for completely neutralized amine functions when the DA does not exceed $50 \%$, which leads to protonation in aqueous acidic solution with a charge density of ${ }_{50}$ the resulting polyelectrolyte dependent on the exact $\mathrm{pH}$ and DDA values. $^{8,9}$



Fig. 1 General preparation of chitosan by deacetylation of chitin under alkaline conditions, which are chosen depending on the biopolymer source and the desired DDA. ${ }^{10}$

65

Perhaps one of the biggest advantages of chitosan as a raw material is that its dilute acidic solutions can be readily cast into films and fibers, or coagulated into well-defined spherical particles by spraying into alkaline solution. While chitosan has 70 been widely used in agriculture, food, and biomedical applications, ${ }^{4,11}$ such physical-chemical versatility and good 
processability has driven its use also in the field of heterogeneous catalysis, especially during the last decade. ${ }^{12}$ The presence of both hydroxyl and amino groups in the chitosan make it useful as a chelating agent. Most studies in this area have focused on 5 exploiting its complexation properties with metal ions and as a polymeric matrix for the synthesis of nanoparticles. ${ }^{12,13,14}$ Although chitosan-supported organocatalysts have been recently reported,${ }^{15}$ the direct use of this amine-containing biopolymer, as a green chemistry approach, ${ }^{16}$ in base catalysis has so far been 10 scarcely investigated. In the other hand, it is known that the chitosan normally has a very low surface area $\left(c a .1 .58 \mathrm{~m}^{2} \mathrm{~g}^{-1}\right)$, their aerogels can display a surface area up to $350 \mathrm{~m}^{2} \mathrm{~g}^{-1}$ with high content of accessible basic sites (up to $5.2 \mathrm{~m}^{2} \mathrm{~g}^{-1}$ of $-\mathrm{NH}_{2}$ groups). ${ }^{17}$ This was exploited by Quignard and co-workers to 15 prepare chitosan aerogel microspheres, obtained under supercritical $\mathrm{CO}_{2}$ conditions, and use them as a catalyst for the synthesis of monoglyceride by fatty acid addition to glycidol in toluene at $70{ }^{\circ} \mathrm{C} .{ }^{18}$ They have also reported very recently the use of chitosan aerogel as a recyclable, heterogeneous organocatalyst 20 for the asymmetric direct aldol reaction in water. ${ }^{19}$ Shukla and co-workers have described the use of powered chitosan, prepared through the hydrogel synthesis route, as a high-temperature catalyst for the synthesis of jasminaldehyde by the ClaisenSchmidt condensation of 1-heptanal and benzaldehyde under 25 solvent-free conditions. ${ }^{20}$ In 2006, some of us showed a preliminary study on the potential of chitosan hydrogel beads (CSHB) as a recyclable organocatalyst for both aldol and Knoevenagel reactions in DMSO.$^{21}$ In the field of low-molecularweight (LMW) gels (i.e. gels made of proline-containing LMW

${ }_{30}$ gelators) as self-supported heterogeneous selective catalysts, the more recent seminal work from Miravet, Escuder and coworkers ${ }^{22}$ should also be featured.

The preliminary studies carried out in our group dealing with the use of CSHB in organocatalysis provided some ambiguous 35 results, which motivated us to investigate this material in more detail. Thus, we report here the results of a comprehensive study aimed to gain a better understanding of the exact role of chitosan hydrogel used directly as a green organocatalyst for $\mathrm{C}-\mathrm{C}$ bond forming reactions (i.e. atom-economical reactions) -which are in 40 the broad sense a prerequisite for all life on earth- and the variables that can impact its performance.

\section{Results and discussion}

\section{Preparation and characterization of the catalyst $\mathrm{t}^{23}$}

Catalyst preparation: In order to evaluate the scope of CSHB 45 as organocatalyst, uniform-size spherical hydrogel beads were prepared by adaptation and optimization of reported procedures based on the alkaline coagulation of an acidic viscous chitosan solution added using a dropping funnel (Fig. 2A). Thus, almost spherical shaped beads with narrow size distribution (average ${ }_{50}$ diameter $=4.0 \pm 0.1 \mathrm{~mm}$ ) were reproducibly obtained by adjusting the distance between the tip of the dropping funnel and the coagulating medium to $1.5 \mathrm{~cm}$ and a falling down rate of drops controlled at approximately one drop per second (Fig. 2BC). CSHB with a mean diameter of $2.2 \pm 0.2 \mathrm{~mm}$ were obtained 55 using a syringe equipped with a $0.8 \mathrm{~mm}$ diameter needle. One of the most critical aspects during the evaluation of the CSHB catalyst is the meticulous washing protocol of the matured beads, thereby ensuring the removal of trapped hydroxyl ions $\left(\mathrm{OH}^{-}\right)$, which otherwise might influence the expected base catalysis by ${ }_{60}$ the free amino groups $-\mathrm{NH}_{2}$ on the chitosan backbone, upon slow diffusion-controlled leaching of $\mathrm{OH}^{-}$during the reaction. In order to demonstrate this hypothesis, different batches of beads at different $\mathrm{pH}$ were prepared by tuning the wash procedure. The exact $\mathrm{pH}$ of the filtrate in each case was measured using a pre65 calibrated $\mathrm{pH}$ meter. The use of previously reported $\mathrm{pH}$ indicators like phenolphthaleine, ${ }^{21}$ proved to be unreliable for this study. ${ }^{23}$ The general correlation of the $\mathrm{pH}$ of the filtrate with the internal $\mathrm{pH}$ of the beads was checked by extensive trituration-dissolution of the beads and measuring the $\mathrm{pH}$ of the resulting solution.

70 Morphology: Scanning electron microscopy (SEM) investigations of the corresponding freeze-dried CSHB showed the heterogeneous porous nature and well-developed networks of the beads with internal pores up to $2 \mu \mathrm{m}$ in diameter (Fig. 2D-E), in contrast to the amorphous structure of commercially powdered 75 chitosan (Fig. 2F). Such heterogeneous and layered structure of the CSHB surface can strongly favour the adsorption of small molecules and ions presented in the medium via electrostatic interactions (non-specific or physical adsorption), hydrogen bonding and/or van der Waals forces. ${ }^{24}$
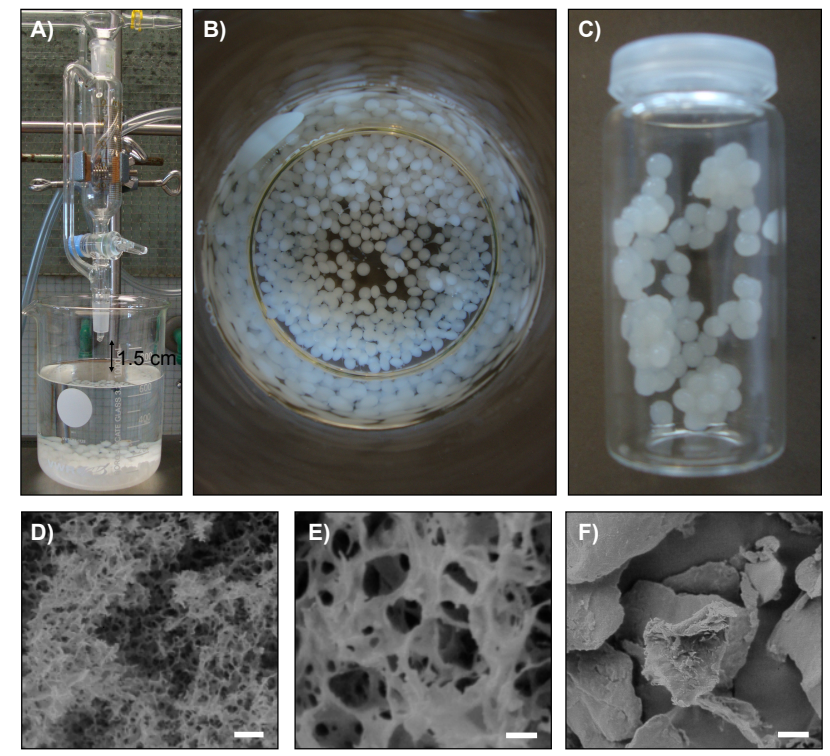

Fig. 2 A) Experimental setup used for the preparation of spherical CSHB with an average diameter of $4.0 \pm 0.1 \mathrm{~mm}$ from commercially LMW chitosan. B) Aspect of CSHB during the maturing process in $\mathrm{NaOH}$ aqueous solution. C) Macroscopic view of milk-white colour CSHB after 85 maturing. D) Representative SEM image of the freeze-dried cryogel beads made from the CSHB (scale bar $5 \mu \mathrm{m}$; magnification 2000X). E) Zoom in of picture D) (scale bar $1 \mu \mathrm{m}$; magnification 10000X). F) SEM image of commercially powdered chitosan (PCS) (scale bar $20 \mu \mathrm{m}$; magnification $500 \mathrm{X})$.

90

The average porosity of the beads regardless the diameter was estimated in $74 \pm 2 \%$, with a calculated moisture content of $94 \pm$ $1 \%$. The aqueous swelling of the chitosan was translated in a much higher percentage of accessible $-\mathrm{NH}_{2}$ groups $(55-65 \%)$ in 95 comparison to both powdered commercially chitosan and dried chitosan beads ( 2.5 and $1.7 \%$, respectively) ${ }^{21}$ which should enhance the potential base catalytic activity of the former. 
FTIR spectroscopy: The FT-IR spectrum of PCS showed the expected bands at $1645 \mathrm{~cm}^{-1}$ (amide $\mathrm{I}, \mathrm{C}=\mathrm{O}$ stretching), $1588 \mathrm{~cm}^{-}$ ${ }^{1}$ ( $\mathrm{N}-\mathrm{H}$ angular deformation of amino groups), $1420 \mathrm{~cm}^{-1}\left(-\mathrm{CH}_{2}\right.$ bending vibration) $1377 \mathrm{~cm}^{-1}(\mathrm{C}-\mathrm{O}$ stretching of primary 5 alcoholic groups - polysaccharides conformation sensitive area-), $1321 \mathrm{~cm}^{-1}$ (amide III), as well as the bands corresponding to the symmetric stretching of C-O-C in the region $1010-1090 \mathrm{~cm}^{-1}$. The broad band between $2990-3600 \mathrm{~cm}^{-1}$ corresponds to $-\mathrm{OH}$ and $-\mathrm{NH}$ stretching adsorption, whereas the aliphatic $\mathrm{C}-\mathrm{H}$ 10 stretching can be observed between $2850-2950 \mathrm{~cm}^{-1}$ (Fig. 3). In the other hand, $4 \mathrm{~mm}$ diameter CSHB showed also the broad but more intense peak between $2990-3650 \mathrm{~cm}^{-1}$ related to the stretching vibrations of the $-\mathrm{OH}$ and $-\mathrm{NH}$ groups also involved in hydrogen bonding. The band at $2881 \mathrm{~cm}^{-1}$ is again attributed to ${ }_{15} \mathrm{C}-\mathrm{H}$ stretching, whereas amide II band, $\mathrm{N}-\mathrm{H}$ bending, $\mathrm{CO}$ stretching of acetyl groups and free $-\mathrm{NH}_{2}$ groups converge in the area between $1600-1645 \mathrm{~cm}^{-1}$.

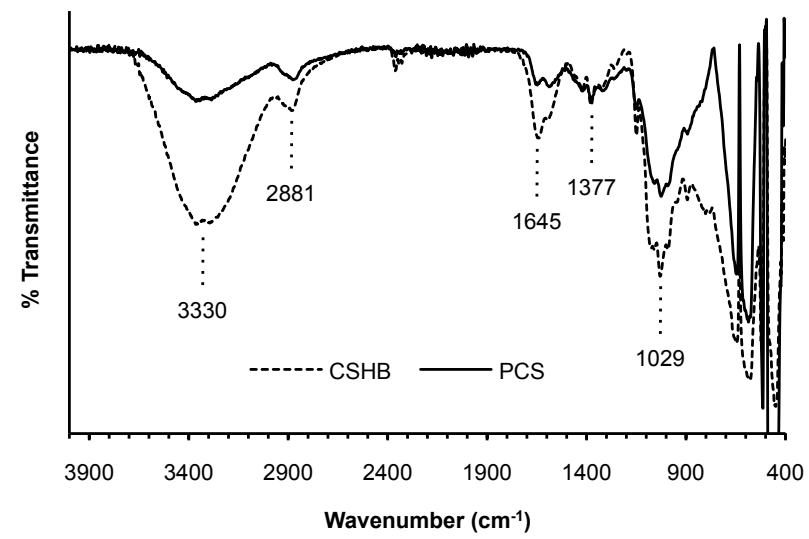

Fig. 3 FT-IR spectra of PCS and CSHB (4 mm diameter).

20 As for PCS, the zeta potential of $\mathrm{CSHB}^{25}$ is also defined by the protonation/deprotonation features of the amine groups since it is positive in acidic solutions and negative in basic solutions, with a point of zero found at about $\mathrm{pH}$ 6.6, which is close to the $\mathrm{p} K_{\mathrm{a}}$ values for the $-\mathrm{NH}_{2}{ }^{26}$

25 Thermal characterization: (1) Thermogravimetric analysis (TGA): TGA curve of CSHB showed expected weight loss at two stages (see ESI). The first one (ca. 95\% weight loss) was found in the region below $250{ }^{\circ} \mathrm{C}$, which is attributed to the water content and in agreement with the estimated value (the weight loss in the

30 same region for solid samples due to absorbed atmospheric water was $c a .1 .8 \%$ ). The second weight loss for CSHB (ca. 2.3\%) was observed in the region between 250 and $450{ }^{\circ} \mathrm{C}$, which is attributed to the decomposition of the polysaccharide chain by comparison with the TGA spectrum of the solid samples ( $c a$. 50-

${ }_{35} 60 \%$ weight loss in the same region). In general, the decomposition temperature of chitosan is molecular weight dependent (the lower the molecular weight, the lower the degradation temperature). ${ }^{27}$ The lower decomposition pattern of the CSXG respect to PCS is attributed to the higher packing 40 density of the former. (2) Differential Scanning Calorimetry (DSC): The DSC thermograms (see ESI) of commercially PCS and CSHB were consistent with the above TGA and literature data. ${ }^{28}$ PCS showed an expected exothermic peak centered at 294 ${ }^{\circ} \mathrm{C}$, which corresponds to the degradation of the biopolymer
${ }_{45}$ backbone, whereas the CSHB showed also a broad endothermic peak centered at $115^{\circ} \mathrm{C}$, which is properly ascribed to the loss of water (the equivalent peak due to evaporation of the absorbed water in PCS was centered at $96{ }^{\circ} \mathrm{C}$ ). The corresponding exothermic peak of the CSHB was centered at $289^{\circ} \mathrm{C}$.

\section{${ }_{50}$ Catalyst performance in the aldol reaction}

Despite the low $\mathrm{p} K_{\mathrm{a}}$ value of the amine group in the chitosan, there are a few aspects that should be taken into consideration when testing the catalytic potential of chitosan-based materials: 1) For monoamines, there is only a single $\mathrm{p} K_{\mathrm{a}}$ value, but for ${ }_{55}$ polyamines the actual number of $\mathrm{p} K_{\mathrm{a}} \mathrm{s}$ is related to the total number of amine groups in the polymer. Thus, the $\mathrm{p} K_{\mathrm{a}} \mathrm{s}$ are used to calculate the overall concentration of conjugate base present for a given amine, ${ }^{29}$ which ultimately is influenced by the polymer polydispersity index (PDI), polymer chain length and the ${ }_{60}$ length of the spacer between amines. 2) In general, amines are more basic in polar aprotic solvents (e.g. DMSO) than in water. In the context of gel systems, it is also worth to consider the potential enhancement of basicity of the system upon gel formation, ${ }^{30}$ which could take place on the aminated surface of ${ }_{65}$ CSHB. 3) The possibility of thermodynamic control in aminecatalyzed Aldol-type reaction involves several reversible steps and a modest exothermicity in reaction with aldehydes, which contribute to the success of the reaction even when weak bases are used to produce only low concentrations of the corresponding 70 nucleophilic intermediates.

Astoundingly, and apparently in contrast with previous observations, ${ }^{21}$ neutral $\mathrm{pH}$ CSHB with average diameters of $4.0 \pm$ $0.1 \mathrm{~mm}$ showed very low activity towards direct aldol reactions between 4-nitrobenzaldehyde (1a) as acceptor and acetone (2) 75 (model reaction I) or cyclohexanone (5) (model reaction II) as donor in DMSO. The reaction was initially run at RT using 17 $\mathrm{mol} \%$ of catalyst ${ }^{23}$ in agreement with previous report. ${ }^{21} \mathrm{~A}$ molar ratio aldehyde:ketone 1:13.6 was employed to minimize selfcondensation of the acceptor and favour cross80 condensantion. ${ }^{18,20,21}$ No product formation was detected in control experiments without catalyst, with dried gel beads instead CSHB or using commercially PCS (see ESI, Table S2). ${ }^{31}$ Nevertheless, instead the expected quantitative conversion of the aldehyde, ${ }^{21}$ only $4 \%$ conversion was achieved after $24 \mathrm{~h} .{ }^{32}$ No ${ }_{85}$ significant improvement was observed neither by increasing three-fold the catalyst loading nor at higher temperature. ${ }^{23}$ The small differences were observed within the experimental error. In spite of the extremely low conversions, the ratio aldol product:dehydration product $(99: 1)$ was in agreement with that 90 previously reported. ${ }^{21,33}$

With this set of data in our hands, and during the preparation of several CSBH batches, we realized that "just" a problem in controlling the washing step in the catalyst preparation could perhaps explain, at least to some extent, the observed enormous ${ }_{95}$ discrepancy with the previous report where phenolphthaleinindicator was used to monitor the $\mathrm{pH}$ of the filtrates. ${ }^{21}$ In order to demonstrate this hypothesis, several CSHB batches were prepared under different washing protocols to guarantee hydrogel beads with different basicity. Thus, $\mathrm{pH}$ depending experiments ${ }_{100}$ could be performed as described in Table 1. Neutral CSHB afforded only $12.3 \%$ (Table 1 , entry 6 ) conversion when 4 nitrobenzaldehyde was used as model substrate, which did not 
show conversion in absence of the catalyst (Table 1, entry 13). In general, the use of slightly basic CSHB resulted in an expected conversion enhancement (Table 1, entries 7, 9, 10, 12), which could be further enhanced by longer reaction times (Table 1, 5 entry $8 v$ v. 7). Such correlation is even reflected in those cases where further washings were done for the beads from the same batch, resulting in a drastic reduction in conversion (Table 1, entry $7 v s$. 1, entry $9 v s .6$ or 2). Therefore, the low activity of the phenolphthalein-indicator at $\mathrm{pH}<8.3$ (colour change interval $=$ $108.3-10$, from colourless at $\mathrm{pH}<8.3$ to fuchsia at higher $\mathrm{pH}$ ) should be taking into consideration in order to ensure the preparation of neutral CSHB, which should be cross-checked with the electrical measurement of the proton concentration inside the beads and/or conductivity measurements of the 15 filtrates. ${ }^{34}$ Hence, we anticipate that the earlier reported aldol conversions using CSHB could be determined under basic conditions rather than neutral due to sufficient trapping of hydroxide ions, ${ }^{21}$ which would indeed enhance the catalysis. This could also explain the drop of the conversion after a second run 20 of the CSHB at pH 7.87 (Table 1, entry 10 vs. 11). In contrast, CSHB batches displaying $\mathrm{pH}$ values between 6.57 and 6.87 showed very little activity in the case of 4-nitrobenzaldehyde (Table 1, entries 1-2) and no activity whatsoever in less activated substrates like 4-chlorobenzaldehyde (Table 1, entry 4) or 225 napthaldehyde (Table 1, entry 5) under identical conditions to those previously reported, ${ }^{21}$ indicating that simply the accessible free primary amino groups presented in these hydrogel beads of the native chitosan are not active enough to promote satisfactorily the formation of the required enamine intermediate ${ }^{35}$ under the 30 present hydrogel conditions. Despite the fact that CSHB would in principle fulfil the requirements to alter the selectivity of the reaction (in the case the beads act as a nanoreactor) ${ }^{36}$ no induction of stereoselectivity due to the chiral backbone of the biopolymer was observed.

Table 1 Correlation between $\mathrm{pH}$ of CSHB and conversion towards the $\beta$ hydroxycarbonyl aldol product ${ }^{a}$

\begin{tabular}{|c|c|c|c|c|c|}
\hline Entry & \multicolumn{2}{|l|}{$\mathrm{ArCHO}$} & $\mathrm{pH}^{b}$ & Time (h) & Conversion $(\%)^{c}$ \\
\hline 1 & 4-Nitrobenzaldehyde & (1a) & 6.57 & 24 & 6 \\
\hline 2 & 4-Nitrobenzaldehyde & (1a) & 6.61 & 24 & 8 \\
\hline 3 & 4-Nitrobenzaldehyde & (1a) & 6.87 & 24 & 4 \\
\hline 4 & 4-Chlorobenzaldehyde & $(1 \mathbf{b})$ & 6.87 & 18 & 0 \\
\hline 5 & 2-Naphthaldehyde & (1c) & 6.87 & 18 & 0 \\
\hline 6 & 4-Nitrobenzaldehyde & (1a) & 7.00 & 24 & 12 \\
\hline 7 & 4-Nitrobenzaldehyde & (1a) & 7.34 & 24 & 39 \\
\hline 8 & 4-Nitrobenzaldehyde & (1a) & 7.34 & 30 & 59 \\
\hline 9 & 4-Nitrobenzaldehyde & (1a) & 7.62 & 24 & 30 \\
\hline 10 & 4-Nitrobenzaldehyde & (1a) & 7.87 & 24 & 45 \\
\hline 11 & 4-Nitrobenzaldehyde & (1a) & 7.87 & 24 & $31^{d}$ \\
\hline 12 & 4-Nitrobenzaldehyde & (1a) & 10.96 & 24 & 42 \\
\hline 13 & 4-Nitrobenzaldehyde & (1a) & $-e$ & 24 & 0 \\
\hline
\end{tabular}

a Reation conditions: 1a-c $(1.0 \mathrm{mmol}), 2$ (1 mL, $13.6 \mathrm{mmol})$, beads 40 number $=20$ (corresponding to $17 \mathrm{~mol} \%$ of free amino groups with respect to aldehyde), DMSO (3 $\mathrm{mL})$, RT. CSHB used in the following entries correspond to the same batch preparation: Entries 1, 8 and 9 (batch
1); entries 2, 6 and 12 (batch 2); entries 11 and 12 (batch 3). ${ }^{b}$ Herein, the reported relative $\mathrm{pH}$ values correspond to the filtrate after washing. ${ }^{c}$ ${ }_{45}$ Determined by ${ }^{1} \mathrm{H}$ NMR of the crude product based on the aldehyde proton (see ESI). Estimated relative error $= \pm 2 .{ }^{d}$ Result of the first recycling of entry $11{ }^{e}$ Control experiment in which no catalyst was employed. Note: The selectivity 3:4 was estimated as 99:1 based on ${ }^{1} \mathrm{H}$ NMR analysis.

To ensure that partial volatilization of acetone (b.p. $=50.5^{\circ} \mathrm{C}$ (a) $760 \mathrm{~mm} \mathrm{Hg}$ ) was not decreasing the reaction rate, we also tested the reaction between $\mathbf{1 a}$ and the non-volatile 55 cyclohexanone (5) (b.p. $=155.7{ }^{\circ} \mathrm{C} @ 760 \mathrm{~mm} \mathrm{Hg}$ ), which has similar basicity in DMSO ( $K_{\mathrm{a}}=26.4$ for 2 and 26.5 for 5) and represents a well-studied substrate for comparison in the same reaction. ${ }^{15 \mathrm{a}, 19}$ Taking into consideration the latest results reported on the use of chitosan aerogels as catalyst for the asymmetric 60 aldol reaction in water, ${ }^{19}$ both DMSO and water were used to evaluate the performance of CSHB. No conversion was observed when the reaction was carried out in absence of any chitosanbased material (Table 2, entries 1 and 3). Similarly, no conversion was observed after $48 \mathrm{~h}$ when commercially LMW ${ }_{65}$ PCS was used in DMSO (Table 2, entry 2 ), and only $8 \%$ when the reaction was carried out in $\mathrm{H}_{2} \mathrm{O}$ (Table 2, entry 4). In the latter case, a moderate anti:syn diastereoselectivity (68:32) was achieved. As expected from these results, the use of PCS in $\mathrm{H}_{2} \mathrm{O}$ :DMSO 1:1 (v/v) afforded almost no conversion whatsoever 70 (Table 2, entry 5). Disappointedly, when we tested our CSHB as catalyst, the reaction conversion was only slightly increased to $13 \%$ in $\mathrm{H}_{2} \mathrm{O}$ (Table 2 , entry 6) with almost not detriment in the diastereoselectivity $(69: 31), 6 \%$ in $\mathrm{H}_{2} \mathrm{O}$ :DMSO $1: 1(\mathrm{v} / \mathrm{v})($ Table 2 , entry 8 ), and $3 \%$ in DMSO (Table 3 , entry 7 ). In the latter case, 75 the anti:syn ratio dropped down ca. $60 \%$ in comparison to the reaction in pure water. Addition of toluene as a co-solvent to improve the solubility of the reactants in the aqueous medium provoked slightly deterioration of both conversion and selectivity (Table 2, entry 9 vs. 6). These findings would be in agreement 80 with the key role of solvent, and especially the beneficial effect of water, in base-catalyzed aldol-type reactions. ${ }^{21,37}$

Table 2 Aldol model reaction II between 4-nitrobenzaldehyde (1a) and cyclohexanone (5) under different conditions ${ }^{a}$

\begin{tabular}{|c|c|c|c|c|}
\hline & $\mathrm{O}_{2} \mathrm{~N}_{1 \mathrm{a}}$ & 5 & $\stackrel{\text { hitosan" }}{\stackrel{\mathrm{O}_{2} \mathrm{~N}^{-}}{\longrightarrow}}$ & $6 a$ \\
\hline Entry & Solvent $^{b}$ & Catalyst & Conversion $(\%)^{c}$ & $\mathrm{dr}(\text { anti/syn })^{d}$ \\
\hline 1 & DMSO & - & 0 & - \\
\hline 2 & DMSO & $\mathrm{PCS}^{e}$ & 0 & - \\
\hline 3 & $\mathrm{H}_{2} \mathrm{O}$ & - & 0 & - \\
\hline 4 & $\mathrm{H}_{2} \mathrm{O}$ & $\mathrm{PCS}^{e}$ & $8\left(46^{g}\right)$ & $69: 31\left(69: 31^{f}\right)$ \\
\hline 5 & $\mathrm{H}_{2} \mathrm{O}:$ DMSO $(1: 1)$ & $\mathrm{PCS}^{e}$ & 2 & $61: 39$ \\
\hline 6 & $\mathrm{H}_{2} \mathrm{O}$ & $\mathrm{CSHB}$ & $13\left(77^{g}\right)$ & $68: 32\left(70: 30^{f}\right)$ \\
\hline 7 & DMSO & CSHB & 3 & $56: 44$ \\
\hline 8 & $\mathrm{H}_{2} \mathrm{O}:$ DMSO $(1: 1)$ & $\mathrm{CSHB}$ & 6 & $70: 30$ \\
\hline 9 & $\mathrm{H}_{2} \mathrm{O}$ :toluene $(4: 1)$ & $\mathrm{CSHB}$ & 9 & $66: 34$ \\
\hline $10^{g}$ & $\mathrm{H}_{2} \mathrm{O}$ & $\mathrm{CSHB}$ & $75^{i}$ & $68: 32$ \\
\hline $11^{h}$ & $\mathrm{H}_{2} \mathrm{O}$ & CSAB & $85^{i}$ & $70: 30$ \\
\hline
\end{tabular}

${ }^{a}$ Reation conditions: 1a $(1.0 \mathrm{mmol}), \mathbf{5}(13.6 \mathrm{mmol}), \mathrm{pH}=6.80$, beads number $=20$ (corresponding to $17 \mathrm{~mol} \%$ of free amino groups with respect to aldehyde), solvent $(3 \mathrm{~mL}), 48 \mathrm{~h}, \mathrm{RT} .{ }^{b}$ The amount of water 90 held by the CSHB ( 20 beads) was estimated in $c a$. $0.5 \mathrm{~mL}$, which is not 
included in the total volume of solvent described in the reaction conditions. ${ }^{c, d}$ Determined by ${ }^{1} \mathrm{H}$ NMR spectroscopy of the crude product. Batch-to-batch estimated relative error $= \pm 0.5 \%$. Relative configurations were assigned by comparison with reported literature data. ${ }^{e}$ Powdered 5 chitosan: $28 \mathrm{mg}$ (corresponding to $17 \mathrm{~mol} \%$ free amino units with respect to aldehyde). ${ }^{f}$ Result obtained under the following conditions: $22 \mathrm{~mol} \%$ free amino groups respect to aldehyde, $1 \mathrm{mmol} \mathrm{1a,} 20 \mathrm{mmol} \mathrm{5}, 0.5 \mathrm{~mL}$ $\mathrm{H}_{2} \mathrm{O}, 48 \mathrm{~h}$, RT. ${ }^{g}$ Data reported in ref. 19 using different CSHB under the conditions specified in footnote $g$. No specific details regarding the o preparation and characterization of those CSHB used were given, which would be necessary for a precise comparison with our beads. ${ }^{h}$ Yield of the $\beta$-hydroxycarbonyl compound $\mathbf{6 a}$ determined by ${ }^{1} \mathrm{H}$ NMR of the crude mixture. ${ }^{i}$ Data reported in ref. 19 using chitosan aerogel beads (CSAB) as catalyst under the conditions described in footnote $h$.

Unfortunately, our CSHB were found to be $c a$. 5 times less effective (in terms of yield but not in terms of selectivity) than the chitosan aerogel, PCS and CSHB formulations reported 20 previously by Quignard and co-workers under analogous conditions (Table 2, entry 6 vs. $10-11$ ). ${ }^{19}$ At this point, and in agreement with previous observations, ${ }^{19}$ we checked that the use of slightly more diluted conditions $(0.2 \mathrm{M} v s .0 .3 \mathrm{M})$, a higher excess of ketone (20 equiv vs. 13.6 equiv) and $5 \mathrm{~mol} \%$ increased 25 catalyst loading, provided a remarkable enhancement of the conversion in both PCS and CSHB-catalyzed processes with almost no variation in the diastereoselectivity (Table 2, entries 4 and 6). Hence, we decided to evaluate which of the different parameters represent a significant contribution to the conversion 30 (Fig. 4). The results of the experimental design clearly showed that only the reaction scale caused a major impact (e.g. $75 \%$ conversion for $\mathbf{F} v s .7 \%$ for $\mathbf{E}$ ).

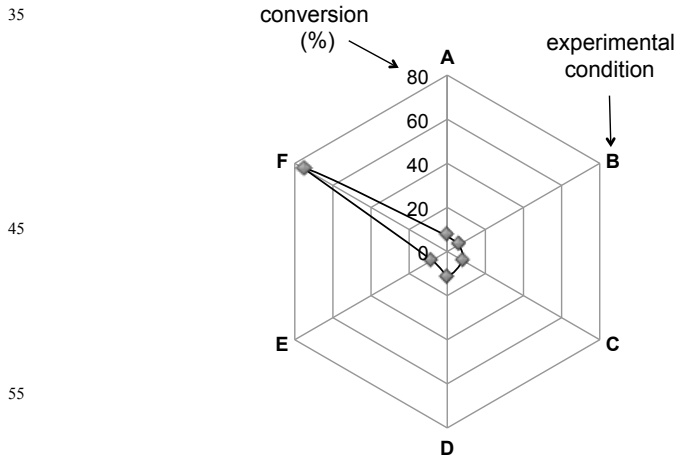

Fig. 4 Radial diagram showing the effect of catalyst loading (B vs. C) molar ratio (A vs. B; C vs. D), concentration (A vs. E) and reaction scale (E vs. F) on the conversion of the aldol reaction between $1 \mathbf{a}$ and $\mathbf{5}$ catalyzed by $4 \mathrm{~mm}$ diameter CSHB. Experimental conditions: $\mathbf{A}=22$ $65 \mathrm{~mol} \%$ catalyst, $1 \mathrm{mmol} \mathrm{1a}, 20 \mathrm{mmol} \mathrm{5}, 0.3 \mathrm{M}$ in $1 \mathbf{a} ; \mathbf{B}=22 \mathrm{~mol} \%$ catalyst, $1 \mathrm{mmol} \mathrm{1a,} 13.6 \mathrm{mmol} \mathbf{5}, 0.3 \mathrm{M}$ in 1a; $\mathbf{C}=17 \mathrm{~mol} \%$ catalyst, 1 mmol 1a, $20 \mathrm{mmol} \mathrm{5,} 0.3 \mathrm{M}$ in 1a; $\mathbf{D}=17 \mathrm{~mol} \%$ catalyst, $1 \mathrm{mmol} \mathrm{1a}$, $13.6 \mathrm{mmol} \mathrm{5,} 0.3 \mathrm{M}$ in 1a; $\mathbf{E}=22 \mathrm{~mol} \%$ catalyst, $1 \mathrm{mmol} \mathrm{1a}, 20 \mathrm{mmol} \mathrm{5}$, $0.2 \mathrm{M}$ in $\mathbf{1 a} ; \mathbf{F}=22 \mathrm{~mol} \%$ catalyst, $0.1 \mathrm{mmol} \mathrm{1a}, 2 \mathrm{mmol} \mathrm{5}, 0.2 \mathrm{M}$ in $\mathbf{1 a}$. 70 Constant conditions: 48 h, RT. Estimated error $= \pm 0.5 \%$.

In the other hand, the effect of the molecular weight of the chitosan was found to be statistically insignificant in this reaction in terms of conversion and selectivity. For example, the use of 75 medium (MMW) or high molecular weight (HMW) PCS lead to $51 \%$ conversion $($ anti $/$ syn $=71: 29)$ or $78 \%$ conversion $($ anti $/$ syn $=$ $68: 32)$, respectively. These values are in the same range than those obtained under the same conditions using LMW PCS (46\% conversion, anti/syn $=69: 31-$ Table 2, entry 4-). A similar 80 behaviour was observed with the hydrogel beads, which lead to $13 \%$ conversion (anti/syn $=70: 30$ ) in the case of MMW chitosan or $7 \%$ conversion (anti/syn $=72: 28$ ) in the case of HMW chitosan (for comparison, see Table 3, entry 6). ${ }^{38}$

With these results in our hands, we decided to explore also 85 some other important variables that could greatly influence the catalyst performance in the case of the hydrogel beads. The foregoing findings and a meticulous study of the experimental details provided for the preparation of similar $\mathrm{CSHB},{ }^{39}$ motivated us to evaluate first the foreseeable effect of the surface area to 90 volume ratio (SA:V) of the CSHB in the aldol reaction rate. For a given shape, high SA:V decreases linearly with increasing size and provides a strong driving force to speed up chemical reactions upon minimization of thermodynamic free energy. In this context, smaller spherical CSHB $(2.2 \pm 0.2 \mathrm{~mm}$ in diameter $)$ ${ }_{95}$ were also tested in the aldol model reactions. However, no significant difference was observed compared to 4-mm CSHB in terms of conversion and selectivity. The results most likely suggests, at least within the studied size range, a basicity mismatch effect rather than a SA:V effect. Moreover, in contrast 100 to the aerogels, ${ }^{19}$ the addition of $20 \mathrm{~mol} \%$ of 2,4 -dinitrophenol as a catalyst for the formation of the enamine intermediate did not provided better results in the case of CSHB (17 mol\%) for the model aldol reaction I (conditions: $18 \mathrm{~h}, \mathrm{RT}$ ).

\section{Knoevenagel reaction}

${ }_{105}$ With the lessons learned from the case of the aldol reaction, we further re-evaluated the neutral CSHB as organocatalyst for the Knoevenagel condensation reaction at RT in DMSO. This modification of the de aldol condensation was tested for an expanded variety of aromatic, heteroaromatic and aliphatic 110 aldehydes in combination with activated methylene compounds as donors including malonitrile $\left(\mathrm{p} K_{\mathrm{a} \text { (water) }}=11.1 ; \mathrm{p} K_{\mathrm{a}(\mathrm{DMSO})}=\right.$ $11.10)$, ethylcyanonacetate $\left(\mathrm{p} K_{\mathrm{a}(\mathrm{DMSO})}=13.10\right)$, barbituric acid $\left(\mathrm{p} K_{\mathrm{a}(\text { water })}=4.01\right)$ and Meldrum's acid $\left(\mathrm{p} K_{\mathrm{a}(\mathrm{DMSO})}=7.33\right)$.

Good to excellent conversions (i.e. $62-100 \%$ ) to the desired 115 condensation product were quickly achieved in the reaction between malononitrile and a variety of aromatic, heteroaromatic and aliphatic aldehydes (Table 3). Thereby, aryl compounds with electron withdrawing groups (e.g. Table 3, entries 1-2) afforded approximately 1.6 -fold higher conversion ${ }^{40}$ rate than those with ${ }_{120}$ electron donating groups (e.g. Table 3, entries 4-5). The desired condensation product was also obtained in good yield with more hydrophobic substrates such as 2-naphthaldehyde (Table 3, entry 3 ). The reaction rates in the case of aliphatic aldehydes (Table 3 , entries 9-10) were comparable to those observed for activated 25 aromatic aldehydes. Double condensation in the case of terephthalaldehyde was also achieved in very good yield without difficulties (Table 3, entry 8). In agreement with previous observations, ${ }^{41}$ heteroaromatic substrates like 2 -furaldehyde were found to react more slowly than other aromatic aldehydes (Table ${ }_{130} 3$, entry 11). It was previously reported that the reaction rates in Knoevenagel condensations are slowed when bulky reagents were used. ${ }^{42}$ However, the use of 2-substituted isomers (Table 3, entries 6-7) provided the same results than the 4-substitued isomers (Table 3, entries 1-2), which indicates a negligible effect ${ }_{135}$ of the steric effect of these 2-substitued isomers in our system, 
albeit other substituents with higher A-values were not evaluated $\left(\mathrm{A}-\right.$ value $_{(\mathrm{Cl})}=0.43 \mathrm{kcal} / \mathrm{mol} ; \mathrm{A}-$ value $\left._{(\mathrm{NO} 2)}=1.1 \mathrm{kcal} / \mathrm{mol}\right)$.

Table 3 Knoevenagel condensation reaction between different aldehydes 5 1a-k and malonitrile (7) catalyzed by CSHB in DMSO at RT

(min)

${ }^{a}$ Reaction conditions: 1a-k $(1.0 \mathrm{mmol}), 7(1.1 \mathrm{mmol})$, DMSO $(3 \mathrm{~mL})$, mean $\mathrm{pH}=6.9$, beads number $=20$ (corresponding to $17 \mathrm{~mol} \%$ of free amine groups with respect to aldehyde), RT. ${ }^{b}$ Determined by ${ }^{1} \mathrm{H}$ NMR 10 spectroscopy of the crude product based on aldehyde proton. Batch-tobatch estimated error $= \pm 0.5 \%$. ${ }^{b}$ Yield previously reported in the literature for the uncatalyzed process in water reaction. Reaction time $=3$ min for entry 2 and 30 min for entry $11 .{ }^{d}$ Experiments using CSHB from different batches with slighly different $\mathrm{pH}$ values: 6.7 for $93 \%$ conversion 15 and 6.5 for $80 \%$ conversion. ${ }^{e}$ Reaction time was not optimized. Conversion calculated respect to malononitrile instead of the aldehyde due to the lower boiling point of the latter.

20 In contrast to some reports in the literature, ${ }^{43,23}$ at least in our hands and using the conditions depicted in Table 3, we could not observe conversion of aldehydes $\mathbf{1 a - 1 b}$ within 5 minutes in pure water and in the absence of any catalyst. In any event, the use of efficient green base-catalysts in aprotic solvents like DMSO 25 would overcome the limitations of working with unstable aldehydes (e.g. aldehydes containing hydrolyzable silanes, aldehydes containing water-sensitive functional groups, aliphatic or water-insoluble aldehydes like 1a-1b with slow kinetic in/on pure water). As a proof-of-concept, highly reactive tert-butyl 30 chloride was quantitatively hydrolyzed to tert-butanol in $0.3 \mathrm{M}$ water after $1.5 \mathrm{~h}$ at $\mathrm{RT}$, whereas it remained stable in DMSO and in the presence of 20 hydrogel beads $\left(17 \mathrm{~mol} \%\right.$ of free $-\mathrm{NH}_{2}$ groups; estimated amount of trapped water $=0.5 \mathrm{~mL}$ ).

As expected, the reactions with ethylcyanoacetate were in 35 general slower than with more acidic malonitrile (Table 4), albeit no difference in terms of catalyst stability was observed in any case. Moreover, only one geometric isomer ( $E$-isomer) was obtained in all cases. Amongst the tested aryl aldehydes, only 4nitrobenzaldehyde reacted quantitatively in 5 minutes (Table 4, 40 entry 1 ). Less activated aldehydes needed $1 \mathrm{~h}$ to react completely (Table 4, entries 2,8), which was not possible with more electron rich aryl substrates even after 5 h (Table 4, entries 4-5). Herein, low reactive substrates like 2-naphthaldehyde produced only modest conversion after $1 \mathrm{~h}$ (Table 4, entry 3). Moreover, the 45 steric effects showed relatively high influence in comparison to the reaction with malonitrile, which can be also overcome with longer reaction times (Table 4, entries 6-7). In general, kinetic rates for activated aromatic aldehydes were found to be higher than for their aliphatic or heteroaromatic partners (Table 4, ${ }_{50}$ entries 9-11). Control experiments carried out in absence of CSHB or in the presence of PCS (Table 4, entry 2) confirmed the utility of the CSHB as heterogeneous catalyst for the Knoevenagel condensation reaction. It is also worth to mention that in none of the cases, side reactions like self-condensation or ${ }_{55}$ Cannizaro products were observed. Although the studied beads showed also activity under solvent-free conditions, the use of solvent clearly facilitates the molecular collisions and the access to the CSHB $-\mathrm{NH}_{2}$ groups (Table 4, entry 11).

60 Table 4 Knoevenagel condensation reaction between different aldehydes 1a-k and ethylcyanoacetate (9) catalyzed by CSHB in DMSO at $\mathrm{RT}^{a}$

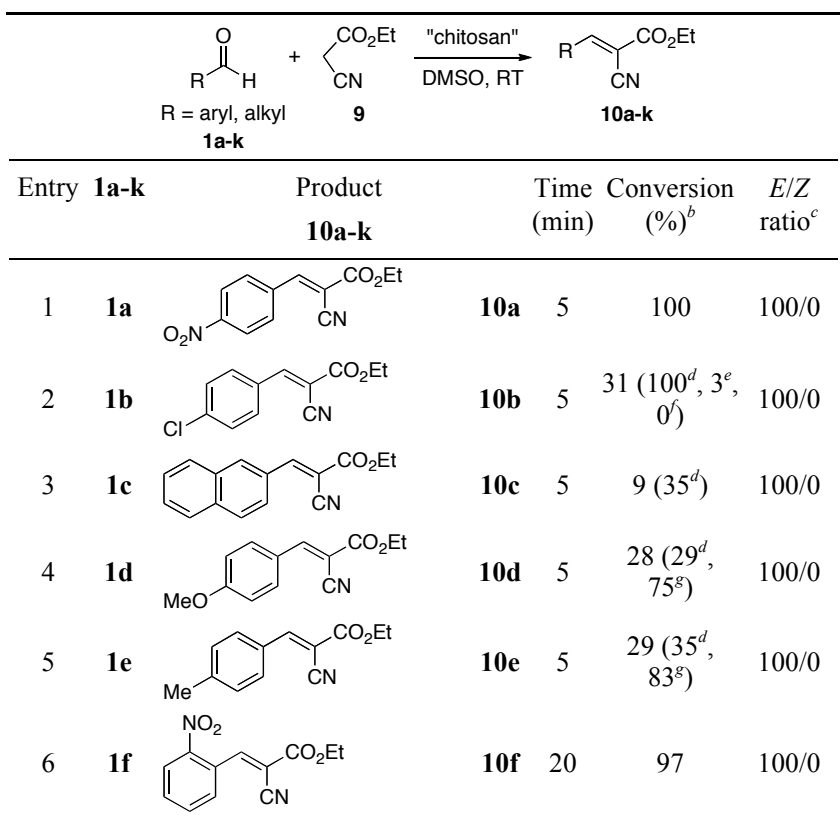






${ }^{a}$ Reaction conditions: 1a-k $(1.0 \mathrm{mmol}), 9(1.1 \mathrm{mmol})$, DMSO $(3 \mathrm{~mL})$, mean $\mathrm{pH}=6.9$, beads number $=20$ (corresponding to $17 \mathrm{~mol} \%$ of free amine groups with respect to aldehyde), RT. ${ }^{b}$ Determined by ${ }^{1} \mathrm{H}$ NMR spectroscopy of the crude product based on aldehyde proton. Batch-to5 batch estimated error $= \pm 0.5 \% .{ }^{c}$ Determined by ${ }^{1} \mathrm{H}$ NMR of the crude product. ${ }^{d}$ Conversion after $60 \mathrm{~min} .{ }^{e}$ Control experiment using PCS (50 $\mathrm{mg}$ ), reaction time $=5 \mathrm{~min} .{ }^{f}$ Control experiment without catalyst, reaction time $=5$ min. ${ }^{g}$ Conversion after 5 h. ${ }^{h}$ Conversion calculated respect to ethylcyanoacetate instead of the aldehyde due to the lower boiling point 10 of the latter. ${ }^{i}$ Conversion obtained under solvent-free conditions (60 min, $\mathrm{RT}$ ).

Kinetics studies of a model Knoevenagel reaction between $\mathbf{1 f}$ 15 and 9 catalyzed by CSHB in DMSO (Table 4, entry 6) led to a first-order rate constant $=4.9 \pm 0.1 \times 10^{-2} \mathrm{~min}^{-1}$, which is in the same range than that reported in the literature for comparable processes. ${ }^{23}$ Moreover, a much lower reaction rate was observed in the case of other activated methylenes containing heterocyclic 20 compounds such as barbituric acid or Meldrum's salt (see ESI, Table S3), most likely due to steric effects.

With the "ideal synthesis/catalysts" concept ${ }^{44}$ in mind, we further evaluated the recovery and reusability of the catalyst in the model condensation between 1a and 7 (Table 5). After the 25 work-up of the reaction, no visible physical changes were observed on the CSHB catalyst surface. The catalyst was found to be easily recovered and retain full activity for at least 4 runs with high TON $(>5800)$ and TOF $\left(>1100 \mathrm{~min}^{-1}\right)$, which indicate both efficient catalyst recovery and good catalyst lifetime. ${ }^{44}$

Table 5 Recycling experiments in the Knoevenagel condensation reaction between $1 \mathrm{a}$ and 7 catalyzed by CSHB in DMSO at $\mathrm{RT}^{a}$

\begin{tabular}{cccccc}
\hline Entry & Catalytic cycle & $\begin{array}{c}\text { Time } \\
(\mathrm{min})\end{array}$ & $\begin{array}{c}\mathrm{Conversion}_{(\%)^{b}} \\
\end{array}$ & $\begin{array}{ccccc}\mathrm{TON}^{c} \\
( \pm 59)\end{array}$ & $\begin{array}{c}\mathrm{TOF}_{\left(\mathrm{min}^{-1}\right)^{d}} \\
( \pm 12)\end{array}$ \\
\hline 1 & Fresh catalyst & 5 & 99 & 5823 & 1164 \\
2 & First cycle & 5 & 99 & 5823 & 1164 \\
3 & Second cycle & 5 & 99 & 5823 & 1164 \\
4 & Third cycle & 5 & 99 & 5823 & 1164
\end{tabular}

${ }^{a}$ Reaction conditions: 1a $(1.0 \mathrm{mmol}), 7(1.1 \mathrm{mmol})$, DMSO $(3 \mathrm{~mL})$, mean ${ }_{35} \mathrm{pH}=6.9$, beads number $=20$ (corresponding to $17 \mathrm{~mol} \%$ free amine units with respect to aldehyde), RT. ${ }^{b}$ Determined by ${ }^{1} \mathrm{H}$ NMR spectroscopy of the crude product based on aldehyde proton. Batch-to-batch estimated error $= \pm 0.5 \% .{ }^{c}$ Turnover number defined as the molar ratio of converted substrate to catalyst loading. ${ }^{d}$ Turnover frequency defined as the molar 40 ratio of converted substrate to catalyst loading per unit of time.
The general greater effectiveness of the Knoevenagel condensation in comparison to the previous aldol reaction ${ }_{45}$ disguises the expected $\mathrm{pH}$ dependence activity in the former. In spite of this, a similar trend of $\mathrm{pH}$-triggered conversion could also be perceived for model Knoevenagel condensations between $\mathbf{1 b}$ and 9 or 1 e and 7 (Table 6).

50 Table 6 Correlation between $\mathrm{pH}$ of CSHB and conversion towards the Knoevenagel product in DMSO at $\mathrm{RT}^{a}$

\begin{tabular}{|c|c|c|c|c|c|c|}
\hline \multirow[b]{2}{*}{ Entry } & ${ }_{\substack{1 b \\
1 e}}^{\stackrel{O}{l}}$ & & $\begin{array}{l}\mathrm{C} \\
\mathrm{N} \\
\mathrm{CN}_{2} \mathrm{Et}\end{array}$ & $\mathrm{HB}$ &  & \multirow[b]{2}{*}{$\begin{array}{c}\mathrm{TON}^{c} \\
( \pm 117) \\
\end{array}$} \\
\hline & Aldehyde & Donor & Product & $\mathrm{pH}$ & $\begin{array}{c}\text { Conversion } \\
(\%)^{b}\end{array}$ & \\
\hline 1 & $1 b$ & 9 & $10 \mathrm{~b}$ & 6.49 & 15 & 882 \\
\hline 2 & $1 b$ & 9 & $10 \mathrm{~b}$ & 6.99 & 31 & 1824 \\
\hline 3 & $1 b$ & 9 & $10 \mathrm{~b}$ & 10.48 & 72 & 4235 \\
\hline 4 & $1 \mathrm{e}$ & 7 & $8 \mathrm{e}$ & 6.49 & 80 & 4706 \\
\hline 5 & $1 \mathrm{e}$ & 7 & $8 \mathrm{e}$ & 6.99 & 87 & 5118 \\
\hline 6 & $1 \mathrm{e}$ & 7 & $8 \mathrm{e}$ & 8.44 & 100 & 5823 \\
\hline
\end{tabular}

${ }^{a}$ Reaction conditions: $\mathbf{1 b}$ or $\mathbf{1 e}(1.0 \mathrm{mmol}), \mathbf{7}$ or $\mathbf{9}(1.1 \mathrm{mmol})$, DMSO (3 $\mathrm{mL}$ ), mean $\mathrm{pH}=6.9$, beads number $=20$ (corresponding to $17 \mathrm{~mol} \%$ free 55 amine units with respect to aldehyde), RT, reaction time $=5$ min. ${ }^{b}$ Determined by ${ }^{1} \mathrm{H}$ NMR spectroscopy of the crude product based on aldehyde proton. Batch-to-batch estimated error $= \pm 0.5 \%$. ${ }^{c}$ Turnover number defined as the molar ratio of converted substrate to catalyst loading.

The concrete participation of the primary $-\mathrm{NH}_{2}$ groups of the chitosan in the aldol-like reactions was further demonstrated by the submitting the CSHB to an imine cross-link process with ${ }_{65}$ glutaraldehyde to form $\mathrm{CS}-\mathrm{N}=\mathrm{CH}\left(\mathrm{CH}_{2}\right)_{3} \mathrm{CH}=\mathrm{N}-\mathrm{CS}{ }^{45}$ This heterogeneous cross-linking reductive amination slightly reduce the positive $\zeta$-potential at $\mathrm{pH}<6.7$ and enhance the mechanical stability of the beads. However, blocking the primary $-\mathrm{NH}_{2}$ groups should cause an erosion of the CSHB for catalysis by 70 decreasing the accessibility of substrate molecules to active basic sites. Indeed, when the model reaction between aldehyde 1f and ethylcyanoacetate $(9)($ Table 4 , entry 6 ; conversion $=97 \%)$ was carried out in the presence of the cross-linked CSHB, the conversion dropped drastically to $c a$. $36 \%$. Some conversion is 75 still observed most probably due to an incomplete imine crosslinking process caused by partial polymerization and/or irreversible entrapment of glutaraldehyde within the cross-linked beads. ${ }^{45}$ However, the foregoing results point out another significant factor that may influence the $-\mathrm{NH}_{2}$ catalysis of CSHB. ${ }_{80}$ The ability of chitosan to readily form imines in the presence of aldehydes under mild conditions could support also a potential change from amine to imine catalysis, at least to a certain extent, with a consequent modification of the surroundings of the active site. Hence, a possible combination of both amine and imine base 85 catalysis (apparently favourable to the former) should be considered in the mechanism of CSHB-catalyzed reactions like Knoevenagel condensations, where imines are usually the key intermediates. In this sense, imine grafted silicas have been already described as mild and effective base catalysts for ${ }_{90}$ Knoevenagel and Michael reactions. ${ }^{46}$ 
At the core of our research perspective, the particular case of biohydrogel materials in catalysis is framed within a scientific challenge devoted towards altering the selectivity of chemical transformations by arranging the potential reactants in organized 5 and confining media. ${ }^{36}$ In combination with the inherent chirality of the chitosan, the high active surface area of CSHB and its 3D porous network might amplify the potential stereoselection in the aldol-like reactions. However, the fact that almost negligible enantiomeric excess $(<1 \%)$ was observed in the aldol reaction

10 may denote a role of the biohydrogel as an immobilized base catalyst instead of a chiral nanoreactor -which is likely the case for aerogel microspheres-. Indeed, no apparent change in lightscattering was observed for CSHB in water between $0{ }^{\circ} \mathrm{C}$ and 60 ${ }^{\circ} \mathrm{C}$, which suggest a permanent close packed structure within that 15 range of temperature. In order to further verify or falsify the above hypothesis we run some model reactions using hemispherical CSHB obtained by cutting in half the original spherical beads. For the same number of beads, the total reactive surface area (SA) will be higher for the hemispherical CSHB

20 (Fig. 5, top). Thus, the comparison between the ratio of the

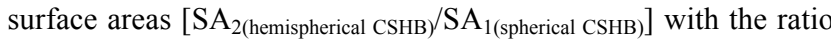
of the specific reaction rates $\left[K_{2 \text { (hemispherical CSHB) }} / K_{1 \text { (spherical CSHB) }} /\right]$ should provide insight about the reaction pathway. No major difference between these ratios would be expected if most of the 25 substrate molecules were transformed on the CSHB surface (Fig. 5 , top path b), whereas a much higher kinetic ratio would underline primary reactivity inside the beads (Fig. 5, top path a). In our case, a fairly good linear correlation between surface area of the CSHB and the ratio of the reaction rates was observed (Fig.

305 , bottom). Thus, the studied CSHB seems to behave most likely as a base-supported catalyst, which is also consistent with the fact that no traces of reaction product could be detected at any reaction time inside the beads. Hence, the modest differences observed between conversions and isolated yields ${ }^{40}$ should be

35 attributed to partial adsorption/absorption of the starting materials onto/inside the beads and/or minor lost during product isolation, mainly due to volatility issues and/or deficient washing steps. In the other hand, the possibility of hydrogen bonding at the surface of the beads between the aldehyde and the water molecules of the

40 hydrogel network could assist the condensation reaction at the water/organic solvent interface.
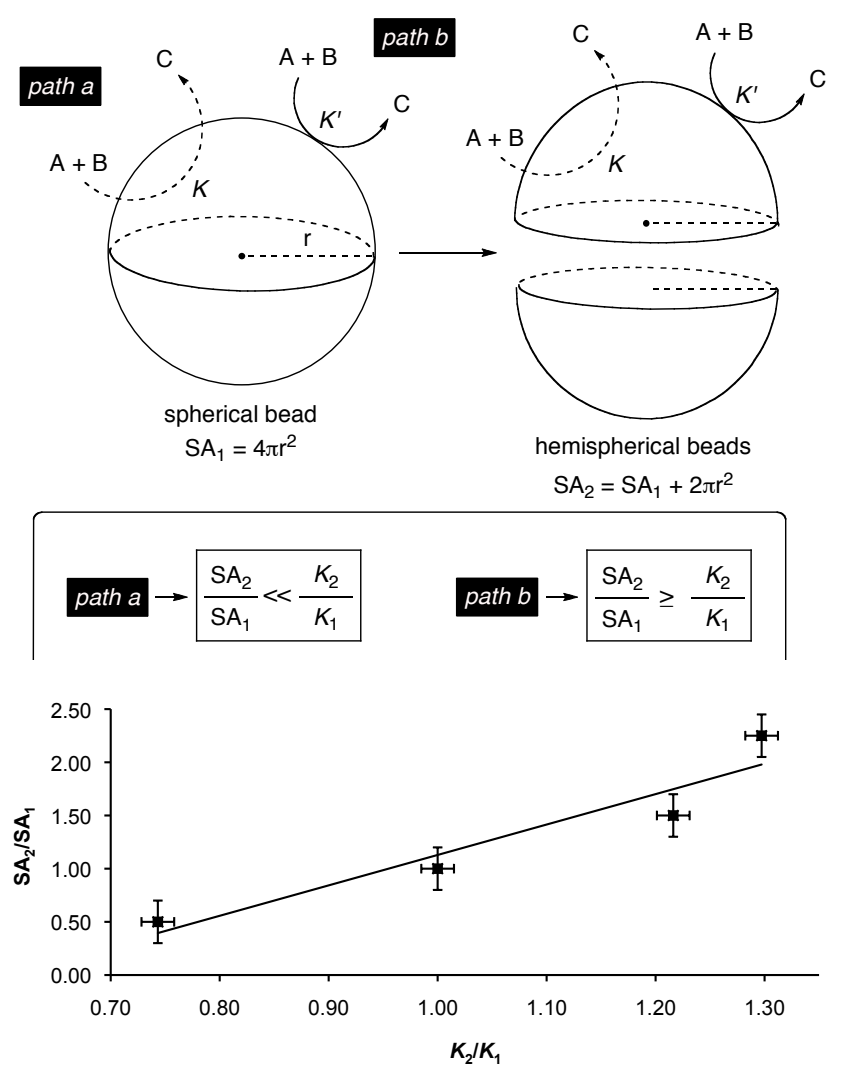

Fig. 5 Top: Relationships between reactive surface areas $\left(\mathrm{SA}_{1}, \mathrm{SA}_{2}\right)$ and reaction rate $\left(K_{1}, K_{2}\right)$ for two potential modes of action of CSHB with 45 diameter r: (1) as a nanoreactor (path a); and (2) as a supported base. Theoretical considerations were made on the base of perfect spherical beads. Bottom: Surface area to reaction rate plot for the Knoevenagel condensation reaction catalyzed by CSHB.

s0 In this regard, UV-vis experiments showed for example a significant adsorption of 4-nitrobenzaldehyde onto CSHB ( $c$ a. 20 mol\% after $1 \mathrm{~h}$ at RT). ${ }^{23}$ Diffusion studies of other small molecules in CSHB have confirmed that the solute transport through the gel beads occurs faster at higher temperatures and ${ }_{55}$ primary by a Fickian diffusion mechanism with general activation energies in the range of $20-30 \mathrm{KJ} / \mathrm{mol}^{47}$ At neutral $\mathrm{pH}$, the negative zeta potential of the CSHB would indeed favour the adsorption of electron-deficient aldehydes. Experiments with metal-doped CSHB have also showed that the catalytic reaction is 60 more likely located on the external layers of catalyst particles. In this case, the strong decrease of kinetic rates with increasing the size of catalytic beads confirms a higher contribution of the resistance to intraparticle diffusion in the control of reaction kinetics. $^{48}$

\section{${ }_{65}$ Nitroaldol (Henry) reaction}

Encouraged by the latter results we decided to evaluate also the CSHB as a heterogeneous catalyst for the classical and valuable nitroaldol (Henry) reaction, which involves the reaction of nitroalkanes with carbonyl compounds (i.e. aldehydes, ketones) 70 in the presence of an ionic or non-ionic base-catalyst to form $\beta$ nitroalcohols under a wide range of experimental conditions. ${ }^{49}$ One of the main drawbacks of this powerful atom-economical 
reaction is the formation of several by-products that complicate the isolation of the desired compounds. These by-products include mainly polymerizable nitroalkenes (formed upon dehydration of the $\beta$-nitroalcohols, especially in the case of aryl aldehydes), self-condensed products in the case of sterically hindered substrates (i.e. Cannizaro reaction), epimerized $\beta$ nitroalcohols and products derived from the Nef reaction. ${ }^{49 a}$ In order to optimize the formation of $\beta$-nitroalcohols, a careful control of the basicity of the reaction medium and long reaction 10 times are usually required. In the case of aromatic aldehydes, the selectivity of the Henry reaction if strongly dictated by the electronic nature of the substituents and their ability to favour either the imine or ion-pair mechanism. ${ }^{49}$

In order to evaluate the performance of the CSHB as an 15 organocatalyst for the Henry reaction, we first investigated the model reaction between 4-nitrobenzaldehyde (1a) and excess nitromethane (11) in the presence of nearly neutral CSHB in both protic and aprotic polar solvents that are frequently used in this transformation (Table 7). As expected, the solvent used did not ${ }_{20}$ show a very large influence on the outcome of the reaction. ${ }^{50}$ The conversion of the reaction was driven to full conversion in $12 \mathrm{~h}$ at RT when either water or DMSO were used as solvent (Table 7, entries 5-6), ${ }^{51}$ whereas in the case of $\mathrm{MeOH}$ or EtOH $24 \mathrm{~h}$ and 30 ${ }^{\circ} \mathrm{C}$ were needed to achieve similar results (Table 7, entries 2, 4). ${ }_{25}$ A temperature increment of only $10{ }^{\circ} \mathrm{C}$ was enough to increase the conversion to the desired nitroaldol product 12a from $33 \%$ to $99 \% \quad$ (Table 7, entry 1 vs. 2 ). Regarding the aldehyde:nitromethane molar ratio, 1:10 was found to be optimum for a catalyst loading of $17 \mathrm{~mol} \%$ (Table 7, entries 2-3).

30 In contrast, equimolar amounts of reactants in $\mathrm{MeOH}$ afforded only $27 \%$ conversion after $24 \mathrm{~h}$ at $30{ }^{\circ} \mathrm{C}$ (Table 7 , entry 3 ). Nearly no conversion was observed when the reaction was run either in $\mathrm{H}_{2} \mathrm{O}$, DMSO or $\mathrm{MeOH}$ in the absence of CSHB (Table 7, entries 7-9). Interestingly, the use of air dried CSHB was also 35 unsuccessful (Table 7, entry 10), whereas the commercially PCS afforded a modest $37 \%$ conversion (Table 7 , entry 11 ). The latter could be driven to $99 \%$ conversion by adding to the reaction mixture approximately the amount of $\mathrm{H}_{2} \mathrm{O}$ estimated in 20 hydrogel beads ( $c a$. 30 equiv of $\mathrm{H}_{2} \mathrm{O}$ respect to the aldehyde)

40 (Table 7, entry 12). As pointed out by Quignard and co-workers, these results could be explained by the dramatic effect that the method used for drying these biomaterials could have on the accessibility of the surface catalytic groups. ${ }^{19}$ In agreement with previous observations for the aldol reaction, almost no ${ }_{45}$ enantiomeric excess $(<1 \%)$ was detected in $\mathrm{MeOH}, \mathrm{H}_{2} \mathrm{O}$ or DMSO either for the nitroaldol version.

Table 7 CSHB-catalyzed model nitroaldol (Henry) reaction in different solvents ${ }^{a}$

\begin{tabular}{|c|c|c|c|c|c|}
\hline \multirow[b]{2}{*}{ Entry } & \multirow{2}{*}{ Solvent } & \multicolumn{2}{|c|}{$\begin{array}{r}\mathrm{H}+\mathrm{CH}_{3} \mathrm{NO}_{2} \\
11\end{array}$} & \multicolumn{2}{|r|}{$12 a$} \\
\hline & & Catalyst & $\mathrm{T}\left({ }^{\circ} \mathrm{C}\right)$ & Time (h) & Conversion $(\%)^{b}$ \\
\hline 1 & $\mathrm{MeOH}$ & CSHB & 20 & 24 & 33 \\
\hline 2 & $\mathrm{MeOH}$ & CSHB & 30 & 24 & $99\left(98^{c}, 80^{d}\right)$ \\
\hline 3 & $\mathrm{MeOH}$ & CSHB & 30 & 24 & $97^{e}, 92^{f}, 78^{g}, 27^{h}$ \\
\hline 4 & $\mathrm{EtOH}$ & CSHB & 30 & 24 & 99 \\
\hline
\end{tabular}

$\begin{array}{cccccc}5 & \mathrm{H}_{2} \mathrm{O} & \mathrm{CSHB} & 25 & 12 & 98\left(15^{i}, 5^{j}\right) \\ 6 & \mathrm{DMSO} & \mathrm{CSHB} & 25 & 12 & 100\left(74^{i}, 33^{j}\right) \\ 7 & \mathrm{H}_{2} \mathrm{O} & - & 25 & 16 & 2 \% \\ 8 & \mathrm{DMSO} & - & 25 & 24 & <1 \% \\ 9 & \mathrm{MeOH} & - & 30 & 24 & 0 \\ 10 & \mathrm{MeOH} & \text { ADCSHB } & 30 & 24 & 0^{k} \\ 11 & \mathrm{MeOH} & \text { PCS } & 30 & 24 & 37^{l} \\ 12 & \mathrm{MeOH} & \text { PCS } & 30 & 24 & 99^{m}\end{array}$

${ }^{a}$ Reaction conditions: 1a $(1.0 \mathrm{mmol}), \mathbf{1 1}(10.0 \mathrm{mmol})$, solvent $(3 \mathrm{~mL})$, mean $\mathrm{pH}=6.9$, catalyst beads number $=20$ (corresponding to $17 \mathrm{~mol} \%$ of free amine groups with respect to aldehyde). ${ }^{b}$ Determined by ${ }^{1} \mathrm{H}$ NMR spectroscopy of the crude product based on aldehyde proton. Batch-to55 batch estimated error $= \pm 0.5 \%{ }^{c}$ Conversion using 15 CSHB units. ${ }^{d}$ Conversion using $10 \mathrm{CSHB}$ units. ${ }^{e}$ Conversion using 7 equiv of 11 respect to $1 \mathrm{a} .{ }^{f}$ Conversion using 5 equiv of 11 respect to $1 \mathrm{a} .{ }^{g}$ Conversion using 3 equiv of $\mathbf{1 1}$ respect to $\mathbf{1 a}{ }^{h}$ Conversion using 1 equiv of $\mathbf{1 1}$ respect to 1a. ${ }^{i}$ Recycling experiment: Conversion after second cycle. ${ }^{j}$ ${ }_{60}$ Recycling experiment: Conversion after third cycle. ${ }^{k}$ ADCSHB $=$ Air dried chitosan hydrogel beads $\left(\mathrm{m}_{(20 \text { units })}=28 \mathrm{mg}\right)$. ${ }^{l}$ Control experiment performed using $28 \mathrm{mg}$ of PCS as catalyst. ${ }^{m} 28 \mathrm{mg}$ of PCS was used as catalyst and $0.54 \mathrm{~mL}$ of $\mathrm{H}_{2} \mathrm{O}$ was added.

65

In contrast to the Knoevenagel condensation reaction, the recycling model experiments carried showed a remarkable catalyst deactivation right after the first virtually quantitative cycle (Table 7, entries 5-6), being even more severe in water than 70 in DMSO. Although the exact deactivation mechanism in the case of hydrogel beads remains unclear, blocking of the basic catalytic sites by chemical poisoning of the surface of the beads seems to play a major role. In this sense, factors like the chemical evolution of intermediate imines, large excess of nitromethane, 75 slow reaction kinetics and the presence of a protic solvent could contribute to the formation of an inactive coat blocking the active surface of the CSHB. In order to support this hypothesis the model nitroaldol reaction between $\mathbf{1 a}$ and $\mathbf{1 1}$ (Table 7, entry 6) was carried out using beads previously matured under three 80 different conditions: (A) beads matured in a solution of 1a (1 $\mathrm{mmol})$ in DMSO (3 mL) for $12 \mathrm{~h}$ at RT; (B) beads matured in a solution of $11(10 \mathrm{mmol})$ in DMSO ( $3 \mathrm{~mL})$ for $12 \mathrm{~h}$ at RT; (C) beads matured in a solution of $1 \mathbf{a}(1 \mathrm{mmol})$ in DMSO $(3 \mathrm{~mL})$ for $5 \mathrm{~min}$ at RT. The conversion values obtained in each case were ${ }_{85} 23 \%$ (A), $95 \%$ (B) and $95 \%$ (C). The results point out that the time in which the reactants are in contact with the beads can be crucial for performance of the catalyst. In agreement to these results, the recycled beads in the case of the Knoevenagel condensation (reaction time $=5 \mathrm{~min}$ ) did not show a major 90 detriment of the catalytic activity. In contrast, the longer reaction time observed in nitroaldol facilitates the blocking of catalytic amine groups. The results of the experiments (A) and (B) point out that the chemical evolution of intermediates imines on the beads surface, by reduction Cannizaro-like processes or 95 formation of cross-linked aminals, play a main role in the catalyst deactivation (Fig. 6, a-b). To a lesser extent, nitroalkanes could be also partially associated to this process since they can interact with the free amine groups by formation of molecular (or chargetransfer) complexes, or with the hydroxyl groups of 100 polysacharides forming nitroalkyl ethers, ${ }^{52}$ which would be in tautomeric equilibrium with the corresponding nitronic acid species (aci-form, $\mathrm{R}^{1} \mathrm{R}^{2} \mathrm{C}=\mathrm{NOOH}$ ). Moreover, the formation of the $a c i$-form is also known to be catalyzed by water ${ }^{53}$ or amines ${ }^{54}$ 
through two stabilizing hydrogen bonds, which could also support the faster catalyst deactivation observed in pure water. Moreover, remarkable stable dimmers of the aci-form could be established like in the case of carboxylic acids. ${ }^{55}$ In any event, the 5 overall effect would be a hindered access to the free amino groups on the surface of the hydrogel beads causing a detriment in the catalytic activity (Fig. 6, c). Moreover, SEM images of the catalytic beads after the nitroaldol reaction suggested the presence of both layered structures and new agglomerated 10 moieties on the surface (Fig. 7). Such clustered structure could be also observed in the case of less active glutaraldehyde crosslinked beads.

(a)

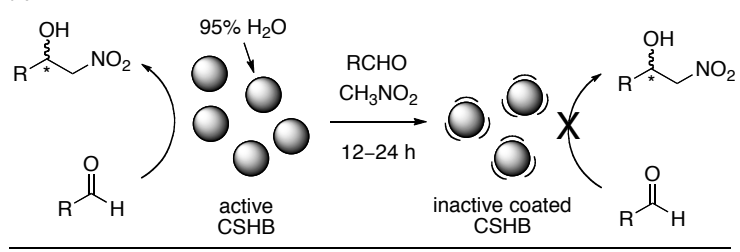

(b)
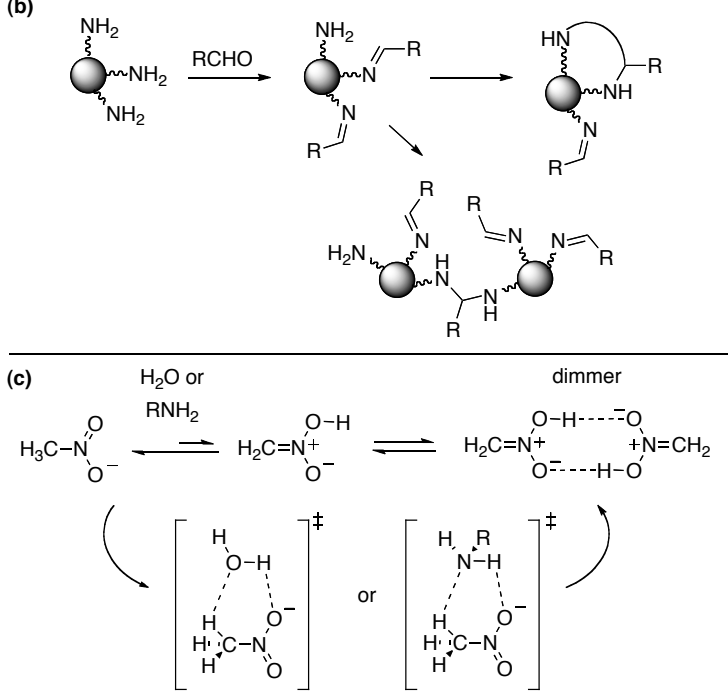

Fig. 6 Plausible contributions to the catalyst deactivation in the nitroaldol 15 reaction (a): formation of lineal or cyclic aminals from intermediate imines (b); formation and H-bonding stabilization of aci-nitromethane catalyzed by hydroxyl or amine groups (c).
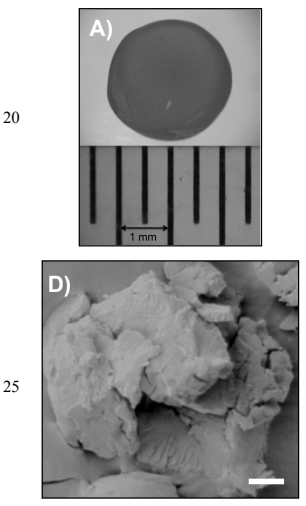
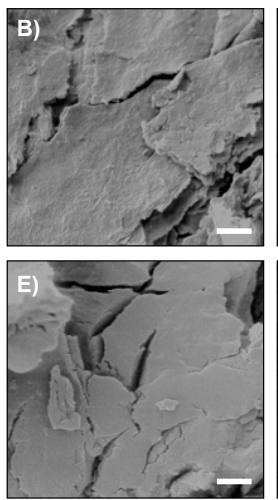
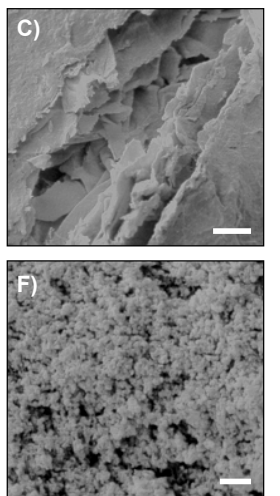

Fig. 7 A) Digital photograph of a CSHB under an optical microscopy (magnification 10X). B-C) Representative SEM images showing the 30 layered surface structure of the CSHB (B: scale bar $20 \mu \mathrm{m}$; magnification 500X; C: scale bar $10 \mu \mathrm{m}$; magnification 1000X). E-F) Representative
SEM images showing the clustered surface structure of the CSHB after the $3^{\text {rd }}$ cycle in the nitroaldol reaction in water (B: scale bar $50 \mu \mathrm{m}$; magnification 200X; C: scale bar $10 \mu \mathrm{m}$; magnification 1000X). F) SEM 35 image of the freeze-dried cryogel beads made from the glutaraldehyde cross-linked CSHB (scale bar $2 \mu \mathrm{m}$; magnification 5000X).

Due to the high toxicity of methanol and the best results obtained in pure water, the latter was used as the green solvent ${ }^{56}$ 40 to study the performance of the biohydrogel catalyst in the Henry reaction with different aldehydes (Table 8). As expected, aldehydes bearing strong electron-withdrawing groups (i.e. 1a, 1f) were converted to the desired nitroaldol product 12 much faster and high TON than less electrophilic aldehydes (i.e. 11, 1b,

${ }_{45} \mathbf{1 g}$ ) (Table 8, entries 2-3 vs. 1, 4-5). For 2-substituted isomers $\mathbf{1 f}$ and $1 \mathrm{~g}$ no major steric effect was observed during the reaction (Table 8 , entries $3,5 v$ s. 2, 4, respectively). In the case of the less reactive chloro-substituted aldehydes like $\mathbf{1 b}$, the conversion could be enhanced to $c a$. $70 \%$ after 4 days at RT or up to $85 \%$ 50 after $24 \mathrm{~h}$ at $40{ }^{\circ} \mathrm{C}$. As it is shown, $\beta$-hydroxy nitroalkane were obtained always as the major product, except for 4methoxybenzaldehyde and furfuraldehyde, which afforded a mixture of nitroalkane and nitroalkene (dehydrated product) in a ratio 2:1 (Table 8, entries 6-7). With aliphatic aldehydes such as 55 isovaleraldehyde (Table 8 , entry 8 ), almost only dehydrated product was detected.

Table 8 CSHB-catalyzed nitroaldol (Henry) reaction between different aldehydes $\mathbf{1}$ and nitromethane (11) in water at $\mathrm{RT}^{a}$

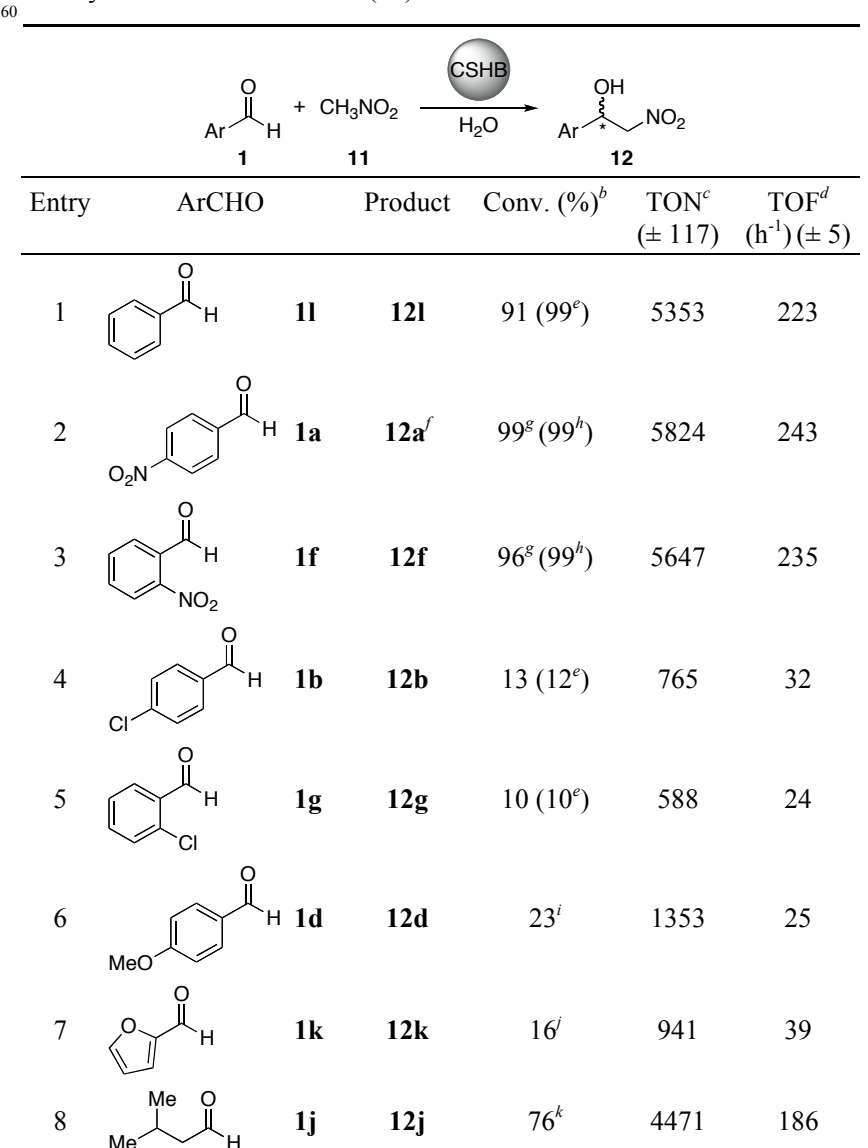

${ }^{a}$ Reaction conditions: Aldehyde (1.0 mmol), $11(10.0 \mathrm{mmol})$, mean $\mathrm{pH}=$ 6.9 , catalyst beads number $=20$ (corresponding to $17 \mathrm{~mol} \%$ of free amine groups with respect to aldehyde), solvent $(3 \mathrm{~mL}), 24 \mathrm{~h}, \mathrm{RT} .{ }^{b}$ Conversion 
was determined by ${ }^{1} \mathrm{H}$ NMR spectroscopy based on aldehyde proton. Batch-to-batch estimated relative error $= \pm 0.5 \%$. ${ }^{c}$ Turnover number defined as the molar ratio of converted substrate to catalyst loading. Turnover frequency defined as the molar ratio of converted substrate to catalyst loading per unit of time. ${ }^{e}$ Conversion obtained using $28 \mathrm{mg}$ of PCS as catalyst after $24 \mathrm{~h} .{ }^{f}$ The enantiomeric excess was determined by chiral-phase HPLC for this model reaction run in: a) DMSO (ee = $0.62 \%)$, b) $\mathrm{MeOH}(\mathrm{ee}=0.34 \%)$, c) $\mathrm{H}_{2} \mathrm{O}$ (ee $=0.05 \%$ ). Conditions: eluent $=n$-Heptane $/ i$-propanol 70/30, flow rate $=0.5 \mathrm{~mL} \mathrm{~min}^{-1}$, wavelength $=$ $10215 \mathrm{~nm}$, run time $=30 \mathrm{~min}$; retention time $(\mathrm{RT}): \mathrm{RT}_{1}=14.34 \mathrm{~min}, \mathrm{RT}_{2}=$ 16.86 min. ${ }^{g}$ Conversion obtained after $12 \mathrm{~h}$ using CSHB as catalyst. ${ }^{h}$ Conversion obtained using $28 \mathrm{mg}$ of PCS as catalyst after $12 \mathrm{~h} .{ }^{i}$ Molar ratio nitroalkane:nitroalkene product $=2: 1$, reaction time $=54 \mathrm{~h} .{ }^{j}$ Molar ratio nitroalkane:nitroalkene product $=2: 1{ }^{k}$ Only dehydrated product 15 with traces of nitroalkane was observed.

We should indicate that our observations made with the commercially PCS in the Henry reaction are in reasonable 20 agreement with the data recently provided by Cui and coworkers. ${ }^{15 \mathrm{~b}}$ Nevertheless, the absence of data regarding the properties of the used chitosan makes very difficult a reliable comparison. For instance, aldehyde $\mathbf{1 f}$ was nearly fully converted into the corresponding nitroalcohol product in $24 \mathrm{~h}$ (Table 8 , 25 entry 4), which was previously obtained in $47 \%$ (isolated yield) in $16 \mathrm{~h}^{15 \mathrm{~b}}$ Under the assumption that the same solid chitosan material was used in both cases (e.g. same molecular weight and DDA), the observed deviations might be justified considering the difference in reaction times (e.g. $24 \mathrm{~h} \mathrm{vs.} 16 \mathrm{~h}$ ) and solvent 30 concentrations (e.g. $0.3 \mathrm{M}$ vs. $0.1 \mathrm{M}$ in aldehyde), as well as possible lost of product during isolation/purification, to which the use of higher amounts of nitroalkane could also contribute (e.g ratio aldehyde:nitromethane 1:10 vs. 1:23). ${ }^{15 \mathrm{~b}}$

We finally confirmed that the size of the nucleophilic ${ }_{35}$ carbanion might play a more critical role than the $\mathrm{p} K_{\mathrm{a}}$ of the donor in the mechanism of the CSHB-catalyzed nitroaldol reaction, in a similar way that has been demonstrated for some enzyme-catalyzed examples. ${ }^{57} \mathrm{We}$ found that the reaction rates and conversions in the presence of CSHB dropped significantly 40 in the case of nitroethane (13) in comparison to nitromethane (11) $\left(\mathrm{p} K_{\mathrm{a}}\right.$ values: $\left.{ }^{57} \mathbf{1 1}=10.2 ; \mathbf{1 3}=8.6\right)($ Table 9$)$. In the other hand, several products were detected by TLC when phenylnitromethane was used as donor, but the NMR analysis of the reaction crude did not allow the unequivocal identification of the signals for the 45 expected product. In general, CSHB performed comparatively better than PCS (Table 9, entry 2). Moreover, the experiments with nitroethane afforded anti/syn ratios 41:59, 45:55 and 45:55 for aldehydes 11, 1a and 1b, respectively, with negligible enantiomeric excess. ${ }^{58}$ Again, a dramatic inactivation of the ${ }_{50}$ catalyst was observed during the recycling experiments (Table 9, entry 3 ).

Table 9 CSHB-catalyzed nitroaldol (Henry) reaction between aldehydes 1 and nitroalkanes 13-14 in water at $\mathrm{RT}^{a}$

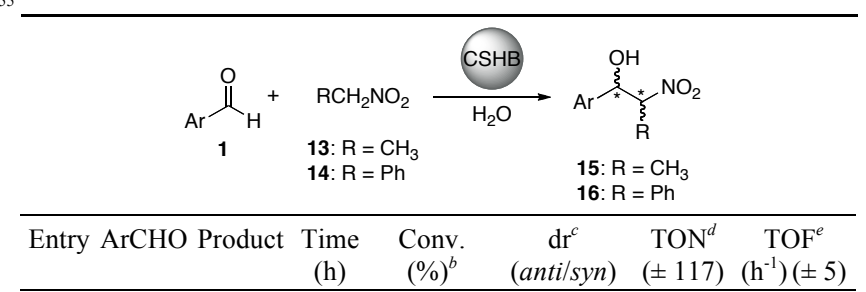

\begin{tabular}{cccccccc}
\hline 1 & $\mathbf{1 1}$ & $\mathbf{1 5 l}$ & 26 & 43 & $41 / 59$ & 2529 & 97 \\
2 & $\mathbf{1 a}$ & $\mathbf{1 5 a}$ & 24 & $\begin{array}{c}85 \\
\left(62^{f}, 2^{g}\right)\end{array}$ & $\begin{array}{c}41 / 59 \\
\left(45 / 55^{f}\right)\end{array}$ & 4470 & 186 \\
& & & & $36^{h}$ & $45 / 55$ & 2118 & 88 \\
3 & $\mathbf{1 a}$ & $\mathbf{1 5 a}$ & 24 & $12^{i}$ & $47 / 53$ & 706 & 29 \\
4 & $\mathbf{1 b}$ & $\mathbf{1 5 b}$ & 26 & 26 & $45 / 55$ & 823 & 32
\end{tabular}

${ }^{a}$ Reaction conditions: Aldehyde $(1.0 \mathrm{mmol}), 13$ or $14(10.0 \mathrm{mmol})$, mean $\mathrm{pH}=6.9$, catalyst beads number $=20$ (corresponding to $17 \mathrm{~mol} \%$ of free amine groups with respect to aldehyde), $\mathrm{H}_{2} \mathrm{O}(3 \mathrm{~mL}), \mathrm{RT} .{ }^{b}$ Conversion was determined by ${ }^{1} \mathrm{H}$ NMR spectroscopy based on aldehyde proton. ${ }^{c}$ 60 Determined by ${ }^{1} \mathrm{H}$ NMR spectroscopy of the crude product. Batch-tobatch estimated relative error $= \pm 0.5 \%$. Relative configurations were assigned by comparison with reported literature data. ${ }^{d}$ Turnover number defined as the molar ratio of converted substrate to catalyst loading. ${ }^{f \mathrm{e}}$ Turnover frequency defined as the molar ratio of converted substrate to 65 catalyst loading per unit of time. ${ }^{f}$ Result of a control experiment performed with $28 \mathrm{mg}$ of PCS as catalyst after $24 \mathrm{~h} .{ }^{g}$ Result of a control experiment performed without catalyst after $24 \mathrm{~h} .{ }^{h}$ Recycling experiment: Conversion after first cycle. ${ }^{i}$ Recycling experiment: Conversion after second cycle.

\section{Michael addition}

Finally, the performance of neutral CSHB was also preliminary evaluated towards two model Michael-like additions involving the reaction between benzylidinemalonitrile (17) and a) 75 cyclohexanone (5) or b) resorcinol (18) in water. The choice of these reactions was made on the basis of the catalytic effect of PCS previously observed in these transformations. ${ }^{59}$ A shown in Table 10 (entry 1), the addition of either 5 or $\mathbf{1 8}$ to $\mathbf{1 7}$ in refluxing water and in the absence of catalyst yielded the corresponding 80 racemic products aminopyrancarbonitrile 19 or chromene 20 albeit in much lower yields. However, the use of both PCS and CSHB under the same conditions afforded the desired products in higher yields (Table 10, entries 2-3). In terms of TON and TOF, no significant differences were observed between CSHB and ${ }_{85}$ PCS, suggesting a similar reactive surface of both catalysts for the Michael reaction under prescribed conditions.

Table 10 Performance of CSHB as organocatalyst in Michael additions in water in comparison with the uncatalyzed and PCS-catalyzed processes ${ }^{a}$

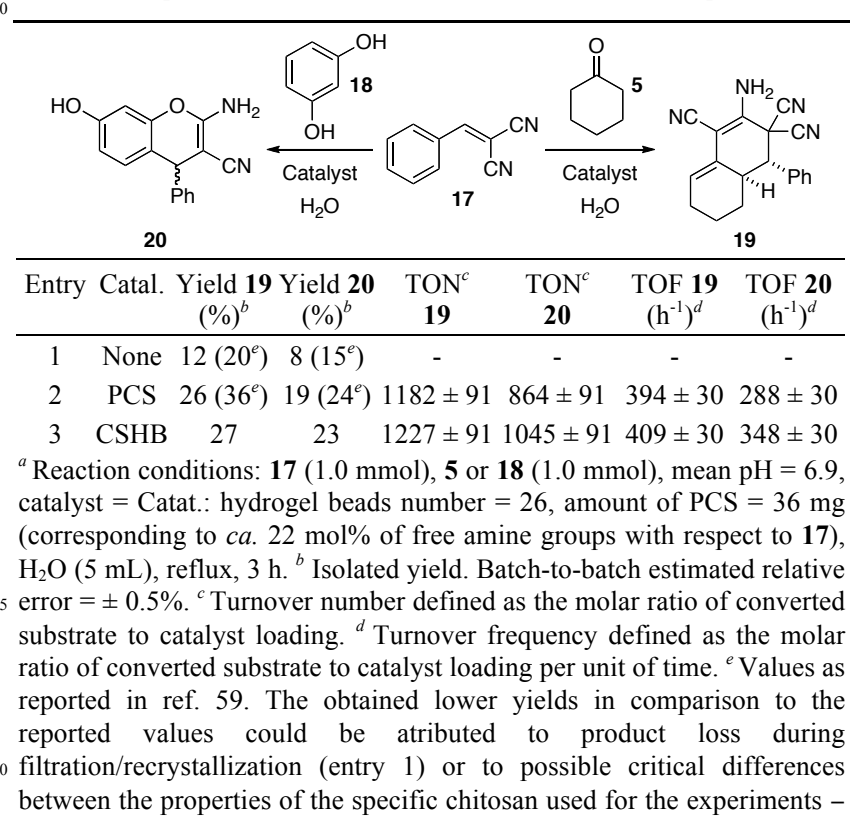


no specific technical data regarding the DDA of the biopolymer were previously reported- (entry 2 ).

Evaluation/optimization of Michael-like addition reactions catalyzed by CSHB, as well as further explorations of the scope and limitations of the direct use of this and related biohydrogels in organocatalysis for biomedical purposes are in progress in our laboratory.

\section{${ }_{10}$ Conclusions}

In conclusion, we have demonstrated that neutral LMW chitosan hydrogel beads with diameters ranging from 2 to $4 \mathrm{~mm}$, is very limited in catalyzing the aldol reaction in both DMSO and aqueous conditions at a catalyst loading of $17 \mathrm{~mol} \%$ (mol\% of 15 free amine groups with respect to aldehyde). A meticulous washing protocol of the matured hydrogel beads was found to be critical to ensure the removal of trapped $\mathrm{OH}^{-}$ions, which otherwise would become the actual catalytic species upon their slow diffusion-controlled leaching during the reaction. The

20 detailed study on the impact of the washing protocol on the catalytic activity of the hydrogel beads aimed also for a better standardization of production process to be able to prepare reproducible CSHB batches.

In contrast, neutral $\mathrm{pH}$ chitosan hydrogel beads displayed high 25 catalytic activity and selectivity in both the Knoevenagel and nitroaldol (Henry) reactions with a variety of acceptors and donors. TONs up to $c a .5823$ were achieved in both cases, whereas the highest TOFs ranged between $c a .1164 \mathrm{~min}^{-1}$ for the Knoevenagel and $c a .243 \mathrm{~h}^{-1}$ for the nitroaldol (Henry) reaction. ${ }_{30}$ In general, higher TONs and TOFs were routinely found for CSHB in comparison to PCS. Experiments with different nitroalkanes revealed that the carbanions with bigger size provided the lower reaction rates and conversions despite the higher acidity of the donor. A similar effect has been also 35 observed in some enzymatic catalysis of this reaction. Nevertheless, the observed negligible enantioselectivites and the reactive surface-reactivity relationship studies confirmed that the biohydrogel beads act as an immobilized base catalyst rather than as a bionanoreactor. In general, no significant correlation between 40 reaction time and selectivity was observed, and neither the SA:V ratio nor the molecular weight of the biopolymer were found to have a major influence on the catalytic performance of the hydrogel beads. Interestingly, CSHB were also found to be catalytically active towards model Michael additions, albeit with ${ }_{45}$ modest TON/TOF comparable to PCS. Optimization of the experimental variables leads to the conclusion that the reaction scale plays a major role in the performance of the biohydrogel catalyst.

Catalytic CSHB are readily available, inexpensive, nontoxic ${ }_{50}$ nonhazardous, and requires no initiation step. In terms of recyclability, the CSHB catalyst could be efficiently recovered after the Knoevenagel condensation reaction by a simple filtration/washing protocol and reused several times without noticeable loss in activity. However, poisoning of the catalyst in 55 the presence of aldehydes and nitroalkanes during extended periods of time was observed, thus seriously hindering its reusability in the nitroaldol (Henry) reaction. Moreover, the direct use of CSHB as organocatalyst could complement the use of other forms of the catalyst (e.g. PCS, CSAB) by (1) being 60 compatible with biodegradable and low toxic organic solvents like DMSO and, therefore, with hydrolysable aldehydes or low reactive aldehydes in aqueous medium, (2) avoiding undesired alterations on the functionalized surface of the biopolymer due to imprecise drying protocols, and (3) enhancing the mechanical ${ }_{65}$ stability of the catalyst due to its elastic properties, without risking the accessibility of the functional groups.

\section{Experimental section}

See ESI for detailed general procedures.

\section{Characterization of new products}

${ }_{70}$ Reaction products $\mathbf{6 a},{ }^{60} \mathbf{8 f},{ }^{61} \mathbf{1 0 e},{ }^{62} \mathbf{1 0 l},{ }^{63} \mathbf{1 0 m},{ }^{64} \mathbf{1 2 d},{ }^{65} \mathbf{1 2 j} \mathbf{j},{ }^{65,66}$ $\mathbf{1 2 k},{ }^{65} \mathbf{1 9}^{59}$ and $\mathbf{2 0}^{59}$ are known compounds and showed spectroscopic data identical with the literature.

2-(Naphthalen-2-ylmethylene)malononitrile (8c): Yellow solid, m.p.: $131-132{ }^{\circ} \mathrm{C} ; R_{f}\left(30 \%\right.$ EtOAc $/ n$-hexane): $0.50 ;{ }^{1} \mathrm{H}$ NMR $75\left(300 \mathrm{MHz}, \mathrm{CDCl}_{3}\right) \delta / \mathrm{ppm}=8.27(\mathrm{~d}, J=1.5 \mathrm{~Hz}, 1 \mathrm{H}), 8.07(\mathrm{dd}, J$ $=8.8,1.9 \mathrm{~Hz}, 1 \mathrm{H}), 8.00-7.84(\mathrm{~m}, 4 \mathrm{H}), 7.65(\mathrm{~m}, 2 \mathrm{H}) ;{ }^{13} \mathrm{C} \mathrm{NMR}$ $\left(75 \mathrm{MHz}, \mathrm{CDCl}_{3}\right) \delta / \mathrm{ppm}=159.8,135.9,134.5,132.6,130.0$, 129.7 (2C), 128.6, 128.1, 127.8, 124.2, 114.0, 112.9, 82.2; FT-IR $v_{\max }\left(\mathrm{cm}^{-1}\right): 2922,2225,1733,1583,1464,1583,1464,1375$, $801270,1185,965,868,810,745$. Anal. Calcd. for $\mathrm{C}_{14} \mathrm{H}_{8} \mathrm{~N}_{2} \cdot 1 / 5$ $\mathrm{H}_{2} \mathrm{O}: \mathrm{C}, 80.91 ; \mathrm{H}, 4.07 ; \mathrm{N}: 13.48$. Found: C, 81.02; H, 4.21; N: 12.73 .

2-(2-Methylpropylidene)malononitrile (8i): Yellow liquid; $R_{f}$ (20\% EtOAc $/ n$-hexane): $0.47 ;{ }^{1} \mathrm{H}$ NMR $\left(300 \mathrm{MHz}, \mathrm{CDCl}_{3}\right.$ ) ${ }_{85} \delta / \mathrm{ppm}=7.14(\mathrm{~d}, J=10.6 \mathrm{~Hz}, 1 \mathrm{H}), 3.02(\mathrm{ddt}, J=13.3,10.6,6.6$ $\mathrm{Hz}, 1 \mathrm{H}), 1.18(\mathrm{~d}, J=6.6 \mathrm{~Hz}, 6 \mathrm{H}) ;{ }^{13} \mathrm{C} \mathrm{NMR}\left(75 \mathrm{MHz}, \mathrm{CDCl}_{3}\right)$ $\delta / \mathrm{ppm}=175.0,112.1,110.4,87.9,32.8,21.0 ;$ FT-IR $v_{\max }\left(\mathrm{cm}^{-1}\right)$ : 2973, 2239, 1734, 1607, 1469, 1367, 1094, 955, 620.

2-(3-Methylbutylidene)malononitrile (8j): Yellowish liquid; ${ }^{1} \mathrm{H}$ $90 \mathrm{NMR}\left(300 \mathrm{MHz}, \mathrm{CDCl}_{3}\right) \delta / \mathrm{ppm}=7.35(\mathrm{t}, J=8.1 \mathrm{~Hz}, 1 \mathrm{H}), 2.50$ (dd, $J=8.0,6.8 \mathrm{~Hz}, 2 \mathrm{H}), 1.94(\mathrm{tt}, J=13.4,6.7 \mathrm{~Hz}, 1 \mathrm{H}), 1.01$ (d, $J$ $=6.7 \mathrm{~Hz}, 6 \mathrm{H})$.

(E)-Ethyl 2-cyano-3-(naphthalen-2-yl)acrylate (10c): Bright yellow solid, m.p.: $111-112{ }^{\circ} \mathrm{C} ; \mathrm{R}_{\mathrm{f}}\left(30\right.$ EtOAc/hexanes): $0.50 ;{ }^{1} \mathrm{H}$ ${ }_{95} \mathrm{NMR}\left(300 \mathrm{MHz}, \mathrm{CDCl}_{3}\right) \delta / \mathrm{ppm}=8.37(\mathrm{~d}, J=6.7 \mathrm{~Hz}, 2 \mathrm{H}), 8.18$ (dd, $J=8.7,1.8 \mathrm{~Hz}, 1 \mathrm{H}), 7.98-7.82(\mathrm{~m}, 3 \mathrm{H}), 7.68-7.51(\mathrm{~m}, 2 \mathrm{H})$, $4.41(\mathrm{q}, J=7.1 \mathrm{~Hz}, 2 \mathrm{H}), 1.42(\mathrm{t}, J=7.1 \mathrm{~Hz}, 3 \mathrm{H}) ;{ }^{13} \mathrm{C} \mathrm{NMR}(75$ $\left.\mathrm{MHz} \mathrm{CDCl}_{3}\right) \delta / \mathrm{ppm}=162.7,155.0,135.4,134.2,132.8,129.4$, $129.2,129.1,129.1,127.9,127.2,125.3,115.8,102.7,62.8,14.2$; ${ }_{100}$ FT-IR $v_{\max }\left(\mathrm{cm}^{-1}\right): 2989,2220,1723,1598,1364,1245,1161$, 1093, 1021, 815, 752. Anal. Calcd. for $\mathrm{C}_{16} \mathrm{H}_{13} \mathrm{NO}_{2}: \mathrm{C}, 76.48 ; \mathrm{H}$, $5.21 ; \mathrm{N}: 5.57$. Found: C, 76.66; H, 5.20; N: 12.66 .

(E)-Ethyl 2-cyano-3-(2-nitrophenyl)acrylate (10f): Off-white solid, m.p.: $99-100{ }^{\circ} \mathrm{C} ; R_{f}\left(30 \%\right.$ EtOAc $/ n$-hexane): $0.32 ;{ }^{1} \mathrm{H}$ $105 \mathrm{NMR}\left(300 \mathrm{MHz}, \mathrm{CDCl}_{3}\right) \delta / \mathrm{ppm}=8.72(\mathrm{~s}, 1 \mathrm{H}), 8.28(\mathrm{dd}, J=8.2$, $1.1 \mathrm{~Hz}, 1 \mathrm{H}), 7.91-7.66(\mathrm{~m}, 3 \mathrm{H}), 4.42(\mathrm{q}, J=7.1 \mathrm{~Hz}, 2 \mathrm{H}), 1.41(\mathrm{t}$, $J=7.1 \mathrm{~Hz}, 3 \mathrm{H}) ;{ }^{13} \mathrm{C} \mathrm{NMR}\left(75 \mathrm{MHz}, \mathrm{CDCl}_{3}\right) \delta / \mathrm{ppm}=161.1$, $153.2,147.4,134.5,132.2,130.6,128.2,125.5,113.9,108.7$, 63.2, 14.1; FT-IR $v_{\max }\left(\mathrm{cm}^{-1}\right): 2999,1721,1604,1570,1519$, 110 1342, 1259, 1200, 1090, 1007, 930, 886, 857, 798. Anal. Calcd. for $\mathrm{C}_{12} \mathrm{H}_{10} \mathrm{~N}_{2} \mathrm{O}_{4}$ : C, 58.54; H, 4.09; N: 11.38. Found: $\mathrm{C}, 58.89 ; \mathrm{H}$, $4.17 ; \mathrm{N}: 11.35$.

(E)-Ethyl 3-(2-chlorophenyl)-2-cyanoacrylate (10g): Beige solid, m.p.: $52-53{ }^{\circ} \mathrm{C} ; R_{f}(30 \%$ EtOAc $/ n$-hexane $): 0.57 ;{ }^{1} \mathrm{H}$ NMR 
$\left(300 \mathrm{MHz}, \mathrm{CDCl}_{3}\right) \delta / \mathrm{ppm}=8.69(\mathrm{~s}, 1 \mathrm{H}), 8.29-8.17(\mathrm{~m}, 1 \mathrm{H})$, $7.55-7.35(\mathrm{~m}, 3 \mathrm{H}), 4.40(\mathrm{q}, J=7.1 \mathrm{~Hz}, 2 \mathrm{H}), 1.41(\mathrm{t}, J=7.1 \mathrm{~Hz}$, $3 \mathrm{H}) ;{ }^{13} \mathrm{C}$ NMR $\left(75 \mathrm{MHz}, \mathrm{CDCl}_{3}\right) \delta / \mathrm{ppm}=161.8,151.2,136.5$, 133.7, 130.4, 129.9, 127.5, 114.9, 106.2, 63.0, 14.2; FT-IR $v_{\max }$ $5\left(\mathrm{~cm}^{-1}\right): 2998,2224,1728,1609,1468,1431,1254,1199,1125$, 1090, 1019, 893, 758.

(E)-Ethyl 2-cyano-4-methylpent-2-enoate (10i): Colourless liquid; $R_{f}\left(20 \%\right.$ EtOAc/ $n$-hexane): $0.52 ;{ }^{1} \mathrm{H}$ NMR $(300 \mathrm{MHz}$, $\left.\mathrm{CDCl}_{3}\right) \delta / \mathrm{ppm}=7.45(\mathrm{~d}, J=10.6 \mathrm{~Hz}, 1 \mathrm{H}), 4.30(\mathrm{q}, J=7.1 \mathrm{~Hz}$, $102 \mathrm{H}$ ), 2.99 (ddt, $J=13.3,10.6,6.6 \mathrm{~Hz}, 1 \mathrm{H}$ ), 1.34 (t, $J=7.1 \mathrm{~Hz}$, $3 \mathrm{H}), 1.15(\mathrm{~d}, J=6.6 \mathrm{~Hz}, 6 \mathrm{H}) ;{ }^{13} \mathrm{C} \mathrm{NMR}\left(75 \mathrm{MHz}, \mathrm{CDCl}_{3}\right) \delta / \mathrm{ppm}$ $=169.2,161.5,113.6,107.5,62.5,31.6,21.3,14.1$; FT-IR $v_{\max }$ $\left(\mathrm{cm}^{-1}\right): 2970,1729,1626,1467,1369,1307,1253,1157,1069$, 1016, 956, 763 .

15 (E)-Ethyl 2-cyano-5-methylhex-2-enoate (10j): Colourless liquid; $R_{f}\left(20 \%\right.$ EtOAc/ $n$-hexane): $0.55 ;{ }^{1} \mathrm{H}$ NMR $(300 \mathrm{MHz}$, $\left.\mathrm{CDCl}_{3}\right) \delta / \mathrm{ppm}=7.66(\mathrm{t}, J=8.0 \mathrm{~Hz}, 1 \mathrm{H}), 4.30(\mathrm{~d}, J=7.1 \mathrm{~Hz}$, $2 \mathrm{H}), 2.45(\mathrm{dd}, J=8.0,6.8 \mathrm{~Hz}, 2 \mathrm{H}), 1.90(\mathrm{dp}, J=13.4,6.7 \mathrm{~Hz}$, $1 \mathrm{H}), 1.34(\mathrm{t}, J=7.1 \mathrm{~Hz}, 3 \mathrm{H}), 0.98(\mathrm{~d}, J=6.7 \mathrm{~Hz}, 6 \mathrm{H}) ;{ }^{13} \mathrm{C} \mathrm{NMR}$ $20\left(75 \mathrm{MHz}, \mathrm{CDCl}_{3}\right) \delta / \mathrm{ppm}=162.8,161.3,113.8,110.4,62.4,40.7$, 28.2, 22.4, 14.1; FT-IR $v_{\max }\left(\mathrm{cm}^{-1}\right): 2969,2876,2231,1730$, 1627, 1466, 1370, 1281, 1256, 1169, 1072, 1048, 836, 758. Anal. Calcd. for $\mathrm{C}_{10} \mathrm{H}_{15} \mathrm{NO}_{2} \cdot 1 / 5 \mathrm{H}_{2} \mathrm{O}: \mathrm{C}, 64.98 ; \mathrm{H}, 8.40 ; \mathrm{N}: 7.58$. Found: C, 65.21; H, 8.33; N: 7.32.

\section{${ }_{25}$ Acknowledgements}

We gratefully acknowledge the financial support rendered by the Alexander von Humboldt Foundation, the University of Regensburg and the Spanish National Research Council (CSIC, project PIE 200980I059). G. S. thanks UGC (India) for a pre30 doctoral fellowship. We also thank the following people: Prof. Pfitzner (UR), Ms Schiessl (UR), Mr. Eiblmeier (UR), Ms. Achatz (UR) and Dr. Müller (UR) for technical assistance during the characterization of the materials, Profs. Cativiela (UNIZAR) Lele (NCL), Marrero-Tellado (ULL) and Finn (TSRI) for support 35 and/or valuable scientific discussions and Prof. Victor Martin (ULL) for providing the photograph of the crab used in the TOC.

\section{Notes and references}

1 R. Höfer, J. Bigorra, Green Chem., 2007, 9, 203-212.

2 M. Elnashar (Ed.), Biopolymers, InTech, 2010.

3 Worldwide production of chitin has been estimated to be approximately $10^{11}$ tons per year, see: K. Kurita, Mar. Biotechnol. 2006, 8, 203-226.

4 M. N.V R. Kumar, React. Funct. Polym., 2000, 46, 1-27.

5 (a) G. A. F. Roberts, Chitin chemistry, 1st Edition, Macmillan, London, UK, 1992; (b) K. Tharanathan, Crit. Rev. Food Sci. Nutr., 2003, 43, 61-87.

6 K. C. Gupta, M. N. V. R. Kumar, J. Appl. Polym. Sci., 2000, 76, 672683.

7 C. Qin, H. Li, Q. Xiao, Y. Liu, J. Zhu, Y. Du, Carbohydr. Polym., 2006, 63, 367-374.

8 A. V. Il'ina, V. P. Varlamov, Appl. Biochem. and Microbiol., 2003, 39, 239-243.

9 Y. Shchipunov, S. Sarin, Il K., C.-S. Ha, Green Chem., 2010, 12, 1187-1195, and references therein.
10 (a) K. Kurita, K. Tomita, T. Tada, S. Ishii, S. Nishimura, K. Shimoda, J. Polym. Sci., Part A: Polym. Chem., 1993, 31, 485-491; (b) M. R. Kasaai, Carbohydr. Polym. 2008, 71, 497-508.

11 H. Honarkar, M. Barikani, Monatsh. Chem. 2009, 140, 1403-1420.

12 D. J. Macquarrie, Ind. Eng. Chem. Res., 2005, 44, 8499-8520.

13 E. Guibal, Prog. Polym. Sci., 2005, 30, 71-109.

14 Y. Liu C. Peng, S. Linyong and Y. Fang. Radiat. Phys. Chem., 2007, 76, 1165-1168.

15 (a) H. Zhang, W. Zhao, J. Zou, Y. Liu, R. Li, Y. Cui, Chirality, 2009, 21, 492-496, and references therein; (b) Y. Cui, H. Zhang, R. Li, Y. Liu. C. Xu, Chinese J. Org. Chem., 2010, 30, 707-712.

16 L. R. MacGillivray, J. L. Reid, J. A. Ripmeester, J. Am. Chem. Soc., 2000, 122, 7817-7818.

17 F. Quignard, R. Valentin, F. Di Renzo, New J. Chem., 2008, 32, 1300-1310.

18 R. Valentin, K. Molvinger, F. Quignard, D. Brunel, New J. Chem., 2003, 27, 1690-1692.

19 A. Ricci, L. Bernardi, C. Gioia, S. Vierucci, M. Robitzer, F. Quignard, Chem. Commun., 2010, 46, 6288-6298.

20 N. Sudheesh, S. K. Sharma, R. S. Shukla, J. Mol. Catal. A: Chem., 2010, 321, 77-82.

21 K. R. Reddy, K. Rajgopal, C. U. Maheswari, M. L. Kantam, New J. Chem., 2006, 30, 1549-1552.

22 (a) F. Rodríguez-Llansola, J. F. Miravet, B. Escuder, Chem. Commun., 2009, 7303-7305. (b) Rodríguez-Llansola, B. Escuder, J. F. Miravet, J. Am. Chem. Soc., 2009, 131, 11478-11484. (c) F. Rodríguez-Llansola, J. F. Miravet, B. Escuder, Chem. Eur. J., 2010, 16, 8480-8486.

23 See ESI for additional details.

24 G. D. Parfitt, C. H. Rochester, in Adsorption from Solution at the Solid/Liquid Interface. Academic Press, Inc.: Orlando, FL; 1983, 913.

25 H. Corcoran, D.-J. Sung, S. Banerjee, Ind. Eng. Chem. Res. 2001, 40, $152-155$.

26 Sudipta Chatterjee, MinW. Lee, Seung H.Woo, Chem. Eng. J., 2009, 155, 254-259, and references therein.

27 M. Shiriu, S. Xintao, U. Florian, S. Michael, B. Dianzhou, K. Thomas, Int. J. Pharm., 2004, 281, 45-54.

28 L. S. Guinesi, É. T. G. Cavalheiro, Thermochim. Acta, 2006, 444, $128-133$.

29 K. M. Delak, N. Sahai, Chem. Mater., 2005, 17, 3221-3227.

30 F. Rodríguez-Llansola, B. Escuder, J. F. Miravet, Org. Biomol. Chem., 2009, 7, 3091-3094.

31 The term "no conversion" has been generally adopted during the entire manuscript to indicate product formation below $1 \%$ as detected by NMR analysis.

32 Such low reaction conversion was also observed if the CSHB were first stirred in the presence of acetone $(30 \mathrm{~min}$ ) before addition of the aldehyde.

33 In general, aldol reactions may be catalyzed either by a base or an acid, where the nucleophile is an enolate anion or enol, respectively. In the latter case, catalytic protonation of the carbonyl oxygen increases the electrophilicity carbonyl carbon just enough so that it can be attacked by the enol, and promote the dehydration of the aldol product, as water is a good leaving group. Nevertheless, it is well known that aldol reactions proceed more efficiently under basic conditions where dehydration rarely takes place during the reaction since hydroxide is a poor leaving group.

34 Under the critical assumption that the content of $\mathrm{Na}^{+}$ions inside the beads reflect the actual hydroxide catalyst content, atomic absorption spectroscopy (AAS) was used to calculate these values for a series of beads that displayed different $\mathrm{pH}$ values of the filtrate after the washing protocol (see Experimental section). Unfortunately, AAS on these materials provided an average value of $9.96 \pm 0.16 \mathrm{ppm}$ of $\mathrm{Na}^{+}$ ions for several batches of beads with $\mathrm{pH}$ values ranging from 6.49 to 8.44 . Therefore, any attend to correlate these AAS values with the actual concentration of hydroxide ions inside the beads 
would not be completely reliable. The same conclusion was derived from ICP measurements of CSHB, from which the theoretical concentration of hydroxide ions (related to the concentration of $\mathrm{Na}^{+}$ ions) would be well below the minimum catalytic loading necessary for the reaction. Although it was not pursued, a more direct method of analysis could involve the treatment of a $\operatorname{Ag}(\mathrm{I})$ solution in the presence of $\mathrm{Mn}(\mathrm{II})$ and finely triturated CSHB. The existence of hydroxide ions in the gel matrix could promote the redox formation of $\mathrm{MnO}_{2}$ and $\mathrm{Ag}(0)$, which could be further quantified by AAS.

35 L.-W. Xu, J. Luo, Y. Lu, Chem. Commun., 2009, 1807-1821, and references therein.

36 D. D. Díaz, D. Kühbeck, R. J. Koopmans, Chem. Soc. Rev., 2011, 40, 427-448.

37 (a) K. Sakthivel, W. Notz, T. Bui, C. F. Barbas III, J. Am. Chem. Soc. 2001, 123, 5260-5267; (b) M. Amedjkouh, Tetrahedron: Asymmetry, 2005, 16, 1411-1414; (c) L. Chao-Jun, Chem. Rev. 2005, 105, 30953165, and references therein; (d) Y. Hayashi, T. Sumiya, J. Takahashi, H. Gotoh, T. Urushima, M. Shoji, Angew. Chem. Int. Ed., 2006, 45, 958-961; (e) Y. Hayashi, Angew. Chem. Int. Ed., 2006, 45, 8103-8104, and references therein; $(f)$ D. Gryko, W. J. Saletra, Org. Biomol. Chem., 2007, 5, 2148-2153.

38 Reaction conditions: $22 \mathrm{~mol} \%$ free amino groups respect to aldehyde, $0.1 \mathrm{mmol} \mathrm{1a}, 20 \mathrm{mmol}$ 5, $0.5 \mathrm{~mL} \mathrm{H}_{2} \mathrm{O}, 48 \mathrm{~h}$, RT.

39 (a) M. Chtchigrovsky, A. Primo, P. Gonzalez, K. Molvinger, M. Robitzer, F. Quignard, F. Taran, Angew. Chemie, 2009, 121, 6030 6034; (b) A. Primo, F. Quignard, Chem. Commun., 2010, 46, 55935595 .

40 For convenience and unless otherwise indicated, conversions are reported instead isolated yields. In general, it was confirmed that $100 \%$ conversion in the present system corresponds to an isolated yield of $c a .80-90 \%$. To ensure that relative conversions could indeed be treated as relative yields, the beads of some selected examples were mechanically destroyed and the residue extensively washed. ${ }^{1} \mathrm{H}$ NMR analysis of the extracts did not show any signal corresponding to the reaction product, but only signals of the starting aldehyde (ca. $8 \mathrm{~mol} \%)$.

41 N. T. S. Phan, C.W. Jones, J. Mol. Catal. A: Chem., 2006, 256, $123-$ 131.

42 G. Jenner, Tetrahedron Lett., 2001, 42, 243-245.

43 M. L. Deb, P. J. Bhuyan, Tetrahedron Lett., 2005, 46, 6453-6456.

44 J. A. Gladysz, Pure Appl. Chem., 2001, 73, 1319-1324.

45 T.-Y. Hsien, G. L. Rorrer, Ind. Eng. Chem. Res., 1997, 36, 36313638 .

46 K. A. Utting, D. J. Macquarrie, New J. Chem., 2000, 24, 591-595.

47 B. Falk, S. Garramone, S. Shivkumar, Mater. Lett., 2004, 58, 32613265.

48 T. Vincent, F. Peirano, E. Guibal, J. Appl. Polym. Sci., 2004, 94, 1634-42, and references therein.

49 (a) F. A. Luzzio, Tetrahedron, 2001, 57, 915-945, and references therein. (b) K. K. Sharma, A. V. Biradar, T. Asefa, ChemCatChem 2010, 2, 61-66, and references therein.

50 L. Kurti, B. Czako, Strategic Applications of Named Reactions in Organic Synthesis. Burlington, MA: Elsevier Academic Press. pp. 202-203, 2005.

51 Additional experiments have shown that $4 \mathrm{~h}$ is enough to achieve practically full conversion in DMSO.

52 A. Heeres, F. F. Spoelma, H. A. van Doren, K. F. Gotlieb, I. P. Bleeker, R. M. Kellogg, Carbohydr. Polym., 2000, 42, 33-43.

53 V. G. Kiselev, N. P. Gritsan, Khim. Fiz., 2006, 25, 54-61.

54 P. Politzer, J. M. Seminario, A. C. Zacarías, Mol. Phys., 1996, 89, 1511-1520.

55 S. Zeman, T. Atalar, Z. Friedl, X.-H. Ju, Cent. Eur. J. Energ. Mater., 2009, 6, 119-133.

56 (a) C. Capello, U. Fischer, K. Hungerbühler, Green Chem., 2007, 9, 927-934. (b) P. J. Dunn, D. A. Perry, Green Chem., 2008, 10, 31-36. (c) Richard K. Henderson, Concepción Jiménez-González, David J. C. Constable, Sarah R. Alston, Graham G. A. Inglis, Gail Fisher, James Sherwood, Steve P. Binks and Alan D. Curzons, Green Chem.,
2011, 13, 854-862. (d) P. G. Jessop, Green Chem., 2011, Advance Article DOI:10.1039/C0GC00797H

57 M. Gruber-Khadjawi, T. Purkarthofer, W. Skranc, H. Griengla, Adv. Synth. Catal., 2007, 349, 1445-1450.

58 (a) T. Purkarthofer, K. Gruber, M. Gruber-Khadjawi, K. Waich, W. Skranc, D. Mink, H. Griengl, Angew. Chem. Int. Ed., 2006, 45, 3454-3456; (b) G. Blay, L. R. Domingo, V. Hernández-Olmos, J. R. Pedro, Chem. Eur. J., 2008, 14, 4725-4730; (c) E. Busto, V. Gotor-Fernández, V. Gotor, Org. Process Res. Dev., 2011, 15, 236240.

59 H. M. Al-Matar, K. D. Khalil, H. Meier, H. Kolshorn, M. H. Elnagdi, Arkivoc, 2008, 288-301.

60 R. Pedrosa, J. M. Andrés, R. Manzano, P. Rodríguez, Eur. J. Org. Chem., 2010, 5310-5319.

61 B. S. Rane, M. A. Kazi, S. M. Bagul, D. P. Shelar, R. B. Toche, M.N. Jachak, J. Fluoresc., 2010, 20, 415-420.

62 J. S. Yadav, B. V. S. Reddy, A. K. Basak, B. Visali, A. V. Narsaiah, K. Nagaiah, Eur. J. Org. Chem. 2004, 546-551.

63 Y. Luo, L. Ma, H. Zheng, L. Chen, R. Li, C. He, S. Yang, X. Ye, Z. Chen, Z. Li, Y. Gao, J. Han, G. He, L. Yang, Y. Wei, J. Med. Chem., 2010, 53, 273-281.

64 T. S. Jin, R.-Q. Zhao, M. Li, Y. Zhao, T.-S. Li, Arkivoc, 2006, 53-58.

65 G. Lai, F. Guo, Y. Zheng, Y. Fang, H. Song, K. Xu, S. Wang, Z. Zha, Z. Wang, Chem. Eur. J., 2011, 17, 1114-1117.

66 For the description of the dehydrated product, see: J.-M. Liu, X. Wang, Z-m. Ge, Q. Sun, T.-m. Cheng, R.-t. Li, Tetrahedron, 2011, 67, 636-640. 